\title{
Article \\ Role of Iron-Containing Alcohol Dehydrogenases in Acinetobacter baumannii ATCC 19606 Stress Resistance and Virulence
}

\author{
Guang-Huey Lin ${ }^{1,2,3}{ }^{\mathbb{D}}$, Ming-Chuan Hsieh ${ }^{1}$ and Hung-Yu Shu ${ }^{4, *}$ \\ 1 Master Program of Microbiology and Immunology, School of Medicine, Tzu Chi University, \\ Hualien 97004, Taiwan; veronica@gms.tcu.edu.tw (G.-H.L.); 105329104@gms.tcu.edu.tw (M.-C.H.) \\ 2 Department of Microbiology, School of Medicine, Tzu Chi University, Hualien 97004, Taiwan \\ 3 International College, Tzu Chi University, Hualien 97004, Taiwan \\ 4 Department of Bioscience Technology, Chang Jung Christian University, Tainan 71101, Taiwan \\ * Correspondence: hyshu@mail.cjcu.edu.tw; Tel.: +886-6-278-5123 (ext. 3211); Fax: +886-6-278-5010
}

check for updates

Citation: Lin, G.-H.; Hsieh, M.-C.; Shu, H.-Y. Role of Iron-Containing Alcohol Dehydrogenases in Acinetobacter baumannii ATCC 19606 Stress Resistance and Virulence. Int. J. Mol. Sci. 2021, 22, 9921. https:// doi.org/10.3390/ijms22189921

Academic Editor: Jorge H. Leitão

Received: 3 August 2021

Accepted: 13 September 2021

Published: 14 September 2021

Publisher's Note: MDPI stays neutral with regard to jurisdictional claims in published maps and institutional affiliations.

Copyright: (C) 2021 by the authors. Licensee MDPI, Basel, Switzerland. This article is an open access article distributed under the terms and conditions of the Creative Commons Attribution (CC BY) license (https:// creativecommons.org/licenses/by/ $4.0 /)$.

\begin{abstract}
Most bacteria possess alcohol dehydrogenase (ADH) genes (Adh genes) to mitigate alcohol toxicity, but these genes have functions beyond alcohol degradation. Previous research has shown that $\mathrm{ADH}$ can modulate quorum sensing in Acinetobacter baumannii, a rising opportunistic pathogen. However, the number and nature of $A d h$ genes in $A$. baumannii have not yet been fully characterized. We identified seven alcohol dehydrogenases (NAD ${ }^{+}$-ADHs) from A. baumannii ATCC 19606, and examined the roles of three iron-containing ADHs, ADH3, ADH4, and ADH6. Marker-less mutation was used to generate $A d h 3, A d h 4$, and Adh6 single, double, and triple mutants. Disrupted Adh4 mutants failed to grow in ethanol-, 1-butanol-, or 1-propanol-containing mediums, and recombinant ADH4 exhibited strongest activity against ethanol. Stress resistance assays with inorganic and organic hydroperoxides showed that $A d h 3$ and $A d h 6$ were key to oxidative stress resistance. Virulence assays performed on the Galleria mellonella model organism revealed that Adh4 mutants had comparable virulence to wild-type, while Adh3 and Adh6 mutants had reduced virulence. The results suggest that $\mathrm{ADH} 4$ is primarily involved in alcohol metabolism, while ADH3 and ADH6 are key to stress resistance and virulence. Further investigation into the roles of other ADHs in $A$. baumannii is warranted.
\end{abstract}

Keywords: iron-containing alcohol dehydrogenase; alcohol metabolism; stress resistance; virulence

\section{Introduction}

Alcohol dehydrogenases (ADHs; EC 1.1.1.1 and EC 1.1.1.2) are widely present in most bacteria [1] and can mitigate the cytotoxicity of aliphatic alcohols such as ethanol, propanol, or 1-butanol [2]. ADHs can be classified by coenzyme into three main types: nicotinamide adenine dinucleotide $\left(\mathrm{NAD}^{+}\right)$-dependent, $\mathrm{NAD}^{+}$-independent, and flavin adenine dinucleotide $\left(\mathrm{FAD}^{+}\right)$-dependent. The $\mathrm{NAD}^{+}$-dependent $\mathrm{ADHs}_{(\mathrm{NAD}}{ }^{+}$-ADHs) can be further subdivided into zinc-containing, iron-containing, and short chain ADHs [3-6]. Interestingly, not all bacteria with ADHs have ethanol-degrading capabilities [7-9], and previous research has shown that bacterial ADHs may have important functions beyond alcohol metabolism, being involved in such diverse mechanisms as stress resistance [10], biofilm formation [11], and bacterial virulence [12].

In addition, several studies have shown that the presence of ethanol can induce stress responses in bacteria that lead to increased virulence [13-15], and this has particularly been noted for Acinetobacter baumannii, a rising opportunistic pathogen that is increasingly seen in nosocomial and community-acquired infections [14,15]. In the presence of ethanol, A. baumannii upregulated the expression of several proteins involved in stress responses, iron assimilation, phosphate transport, and lipid and carbohydrate anabolism; while at the same time, increased secretion of phospholipase $C$, acidification of bacterial cultures, and 
formation of biofilms was also noted [14,15]. The main A. baumannii Adh gene (A1S_2098) was strongly induced in the presence of ethanol, but other genes potentially encoding $\mathrm{ADHs}$, including two iron-containing ADHs (FeADHs), were not induced or only slightly upregulated [14], and this suggests that these ADHs may have functions beyond ethanol degradation. Importantly, it was found that ethanol-exposed A. baumannii demonstrated stronger virulence in a Galleria mellonella model of infection [15]. A recent study has also shown that the A1S_2098 gene is significantly upregulated during the A. baumannii biofilm formation process, and may play a role in quorum sensing, bacterial growth, and motility [11]. However, the number and nature of other A. baumannii genes potentially encoding ADHs, particularly FeADHs, has not yet been explored in detail.

In this study, we sought to elucidate the roles of three A. baumannii genes identified through in silico methods as potentially encoding FeADHs, and assessed the impact of their expression products on ethanol metabolism, stress responses, and virulence. These results can help to bridge the gaps in our current understanding of ADH function in $A$. baumannii, and may serve as the basis for future research into other as yet uncharacterized Adh genes. In the long term, the results of such research could potentially advise more effective sanitizing procedures and infection control measures, in order to prevent the survival and spread of A. baumannii in both clinical and community settings.

\section{Results}

\subsection{In Silico Identification of Putative ADH Genes in A. baumannii}

A search of the GenBank database revealed seven genes annotated as possible Adh genes in A. baumannii (Table S1). Genomic analysis revealed that three of these are ironcontaining $\mathrm{ADHs}(\mathrm{ADH} 3, \mathrm{ADH} 4$, and $\mathrm{ADH} 6$ ), another three are zinc-dependent $\mathrm{ADHs}$ (ADH1, ADH2, and ADH7), and the remaining one is a short-chain ADH (ADH5). The iron-containing ADHs were respectively encoded by DJ41_189 (ADH3; 1,158 bp), DJ41_136 (ADH4; 1,173 bp), and DJ41_1604 (ADH6; 1,185 bp). Interestingly, the number of annotated Adh genes is relatively low in terms of the genome size of $A$. baumannii (genome size 3.97 Mb, 7 Adh genes annotated in GenBank), as other Gram-negative soil bacteria that are also opportunistic pathogens have significantly more annotated Adh genes, with 44 Adh genes found for Burkholderia psedomallei K96243 (7.42 Mb genome) and 42 Adh genes annotated for Pseudomonas aeruginosa PAO1 (6.26 Mb genome). However, this may be indicative of limited research conducted in A. baumannii, and further studies are needed to better examine this phenomenon.

Phylogenetic analysis was conducted with 26 annotated ADH amino acid sequences from 14 microorganisms that were identified in a comprehensive search of the GenBank database, and MEGA 7 software (https:/ / www.megasoftware.net/, accessed on 31 July 2021) was used to construct a phylogenetic tree. The resulting dendrogram revealed two discrete iron-containing and zinc-containing clades (Figure 1). Of the iron-containing ADHs identified in A. baumannii, ADH4 was found to distribute in the same clade as ADH from ethanologenic microorganisms, including Saccharomyces cerevisiae (Figure 1A). ADH3 and ADH6 shared higher identity with bifunctional aldehyde-alcohol dehydrogenases (Figure 1A). Proteomic analysis showed that ADH3 shared 31.7\% identity with ADH4, and $30.6 \%$ identity with ADH6, while ADH4 and ADH6 shared 33.1\% identity (Figure 1B). The cofactor binding motif, GGGSXXD, four key iron-binding sites $(\mathrm{D}, \mathrm{H}, \mathrm{H}, \mathrm{H})$, and a highly conserved aspartic acid residue (D; located at position 39 in ADH3, position 46 in ADH4, and position 41 in ADH6) were found in all three FeADHs, and indicate the preference for NAD+ as a cofactor for these enzymes (Figure 1B). 


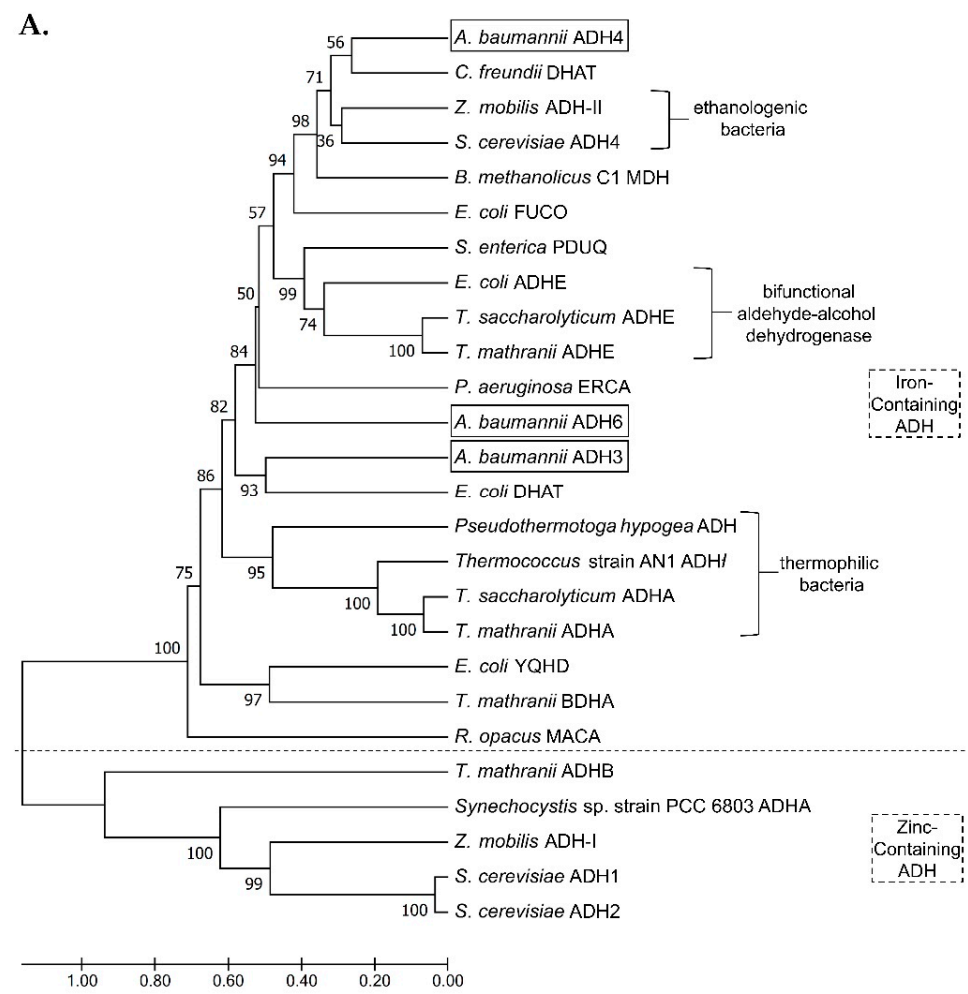

B.

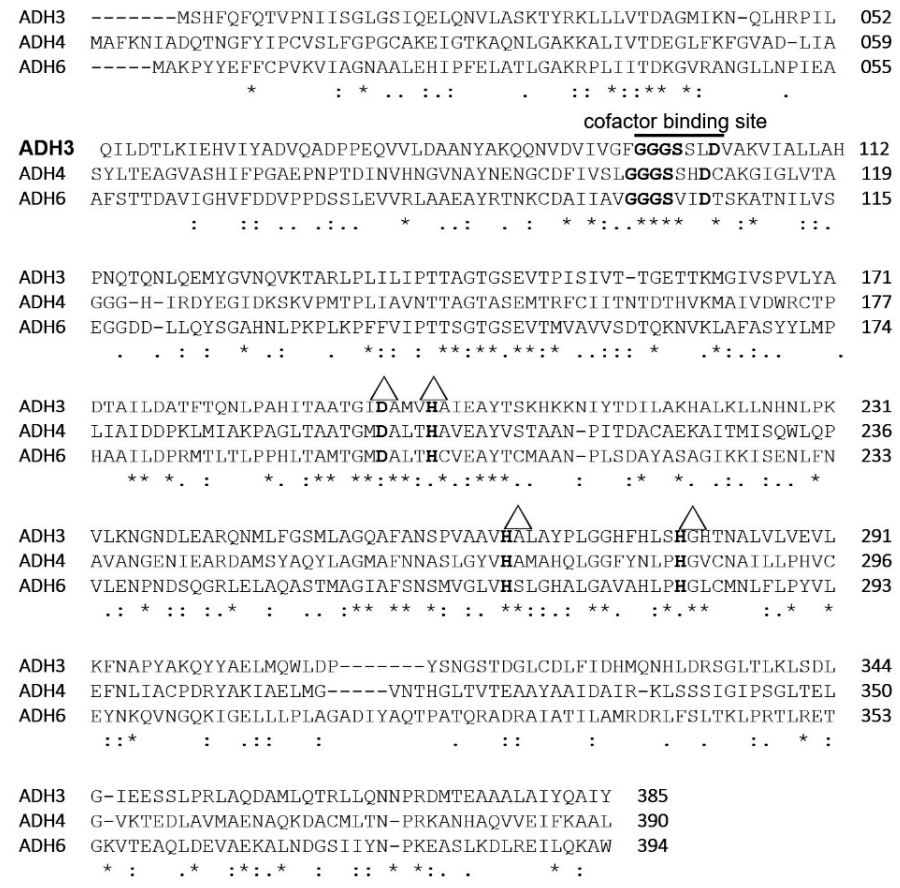

Figure 1. (A) Cladogram of iron-containing Adh genes in A. baumannii compared with 23 other Adh genes from 14 organisms. The scale bar indicates the number of nucleotide substitutions per site. (B) Amino acid alignment of three FeADHs (ADH3, ADH4, ADH6) in A. baumannii. $\Delta$ indicates the positions of the four key iron-binding sites $(\mathrm{D}, \mathrm{H}, \mathrm{H}, \mathrm{H})$. Asterisks $\left(^{*}\right)$ indicate positions with single fully conserved amino acid residues; colons (:) indicate positions with conservation between residues of strongly similar properties (scoring $>0.5$ in the Gonnet point accepted mutation 250 matrix); and periods (.) indicate positions with conservation between groups of weakly similar properties (scoring $\leq 0.5$ in the Gonnet point accepted mutation 250 matrix). 


\subsection{Biochemical Properties of ADH4}

To understand the biochemical properties of these three FeADHs, we cloned their encoding genes into plasmid PQE80L, then transformed plasmids into E. coli for protein overexpression and subsequent purification. Overexpression was successfully induced for all FeADHs (Figure S1, lanes 2, 5, 8), and soluble proteins were purified by Ni-affinity chromatography, with protein sizes of about $43.7 \mathrm{kDa}, 44.2 \mathrm{kDa}$ and $44.7 \mathrm{kDa}$, respectively (Figure S1, lanes 3, 6, 9).

The enzymatic activity of ADH4 was tested in different buffers, as well as varying temperature conditions, in order to establish the optimal conditions for enzymatic activity assays against different alcohol substrates. We tested $0.5 \mu \mathrm{M}$ of $\mathrm{ADH} 4$ in $80 \mu \mathrm{M}$ of three different buffers (Figure 2A), and the highest activity was noted with the CB buffer at a $\mathrm{pH}$ value of 10.1 (Figure 2A). In addition, maximal ADH4 activity was detected at $37^{\circ} \mathrm{C}$ (Figure 2B). Using these conditions, we proceeded to assess the substrate specificity of recombinant ADH4 against ethanol, 1-propanol, and 1-butanol, and subsequently found that the Michaelis-Menten constant $\left(K_{M}\right)$ was lowest for ethanol (Table 1; Figure S2), indicative of stronger affinity to ethanol for ADH4 over other aliphatic alcohols.
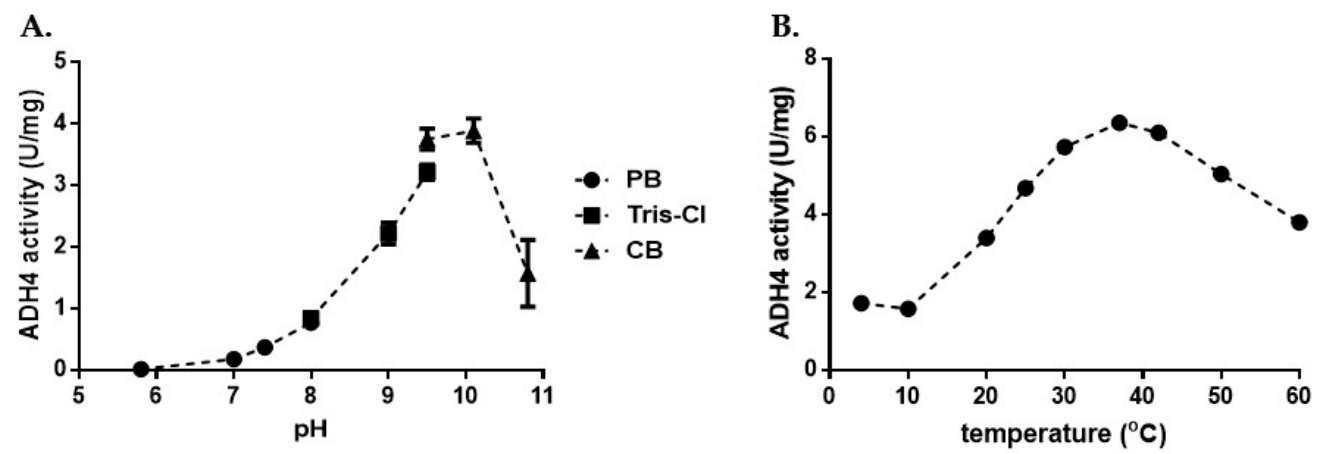

Figure 2. (A) Optimum $\mathrm{pH}$ conditions for $\mathrm{ADH} 4$ enzymatic activity. ADH4 enzymatic activity was assessed at room temperature under the following $\mathrm{pH}$ ranges: Tris- $\mathrm{Cl}$ : $\mathrm{pH}=5.8-8$; $\mathrm{PB}$, phosphate buffer: $\mathrm{pH}=8-9.5$; $\mathrm{CB}$, carbonatebicarbonate buffer: $\mathrm{pH}=9.5-10.8$. The production of $1 \mu$ mole of $\mathrm{NADH}$ was defined as 1 unit of ADH activity. (B) Optimum temperature of ADH4 enzymatic activity. ADH4 enzymatic activity was assessed for different temperatures at the optimum $\mathrm{pH}$ of 10.8 in CB buffer.

Table 1. Alcohol substrate specificity of ADH4.

\begin{tabular}{cccc}
\hline & \multicolumn{3}{c}{ Carbonate-Bicarbonate (CB) Buffer, $\mathbf{p H}=\mathbf{1 0 . 1}$} \\
\cline { 2 - 4 } & Ethanol & 1-Propanol & 1-Butanol \\
\hline$V_{\max }\left(\mathrm{mmole} \mathrm{min}^{-1}\right)$ & $0.0064 \pm 0.0002$ & $0.027 \pm 0.0028$ & $0.005 \pm 0.001$ \\
$K_{M}(\mathrm{mM})$ & $5.11 \pm 0.71$ & $206.8 \pm 79.61$ & $196.5 \pm 91.21$ \\
$k_{\text {cat }}\left(\mathrm{s}^{-1}\right)$ & 0.2118 & 0.9003 & 0.1683 \\
$k_{\text {cat }} / K_{M}\left(\mathrm{~s}^{-1} \mathrm{M}^{-1}\right)$ & 41.4481 & 4.3535 & 0.8565 \\
\hline
\end{tabular}

\subsection{Biological Function of $A D H 3, A D H 4$, and $A D H 6$}

To elucidate the biological roles of $A d h 3, A d h 4$ and $A d h 6$, we generated three single mutants $(\Delta 3, \Delta 4, \Delta 6)$, three double mutants $(\Delta 34, \Delta 36, \Delta 46)$, and one triple mutant $(\Delta 346)$ using marker-less mutation. Mutants were confirmed by colony PCR (Figures S3 and S4) with gene-specific primers (Table 2). Growth rates of these seven mutants in LB medium did not differ from wild-type, suggesting that FeADHs did not play a major role in growth and survival under culturing conditions with rich medium (Figure 3A). However, strains with mutated Adh4 failed to proliferate in M9 medium containing 1\% ethanol (Figure 3B), in line with the findings in Table 1 that point to a role for ADH4 in ethanol metabolism. Moreover, all strains with mutated Adh4 failed to proliferate in medium containing $1 \%$ of 1-propanol, while $\Delta 3$ and $\Delta 36$ mutants experienced reduced growth rates compared to 
wild-type (Figure 3C). Interestingly, the $\Delta 6$ mutant had comparable growth rates as wildtype, suggesting that both $\mathrm{ADH} 3$ and $\mathrm{ADH} 4$ may have roles in 1-propanol metabolism. All mutant strains had reduced growth compared to wild-type in medium containing $1 \%$ of 1-butanol (Figure 3D).

Table 2. Gene-specific primers used in this study.

\begin{tabular}{ccc}
\hline Name & Sequences $\left(5^{\prime}-\mathbf{3}^{\prime}\right)$ & Function \\
\hline pK18_Adh3upF & CGAGCTCGGTACCCGGGACGCCCTTTAACATGACCAG & Construction of Adh3 mutant \\
pK18_Adh3downR & AACGACGGCCAGTGCCACAGATGCGCTAAGGGAAAAC & Construction of Adh3 mutant \\
pK18_Adh4upF & CGAGCTCGGTACCCGGGTGCCCTTCATTATCAATTTCG & Construction of Adh4 mutant \\
pK18_Adh4downR & AACGACGGCCAGTGCCAGACATCGCTTTGAGTTGCAT & Construction of Adh4 mutant \\
pK18_Adh6upF & CGAGCTCGGTACCCGGGACGCACATTGGTCAGTTTTG & Construction of Adh6 mutant \\
pK18_Adh6downR & AACGACGGCCAGTGCCATTGCTGCAACCATAACAGGT & Construction of Adh6 mutant \\
Adh1_rF & TGTGATTGCCTGTGGTGAAT & qRT-PCR \\
Adh1_rR & ACACCGCCGTAAAGATGACT & qRT-PCR \\
Adh2_rF & GGTCGATTCATGCCGTACTT & qRT-PCR \\
Adh2_rR & TGTGGTAATACCCGCACAAA & qRT-PCR \\
Adh3_rF & TCAGTTACACCTGCCTATTCTTCA & qRT-PCR \\
Adh3_rR & CCCAAAGCCGACAATAACAT & qRT-PCR \\
Adh4_rF & TGCAAGATGAAGGGCTATTT & qRT-PCR \\
Adh__rR & CACCGCCTAACGACACAATA & qRT-PCR \\
Adh5_rF & GCCAGCAGATAAAGCGGATT & qRT-PCR \\
Adh5_rR & TGTTGCCCCATATACATTACCA & qRT-PCR \\
Adh6_rF & TCTGGTGCACACAACCTACC & qRT-PCR \\
Adh__rR & TCTAAAATCGCAGCATGTGG & qRT-PCR \\
Adh7_rF & GGCGAAAATATCGCAACAAT & qRT-PCR \\
Adh7_rR & ACCCAAACCACCAATACCAA & qRT-PCR \\
pRsetB-His7-Peredox-mCherry_F & GCCCTTTCGTCTTCAAGTAATACGACTCACTATAGGG & Construction of peredox plasmid \\
pRsetB-His7-Peredox-mCherry_R & AGCTGTCAAACATGAGTCACTTGTACAGTTCGTCCA & Construction of peredox plasmid \\
\hline
\end{tabular}

A.

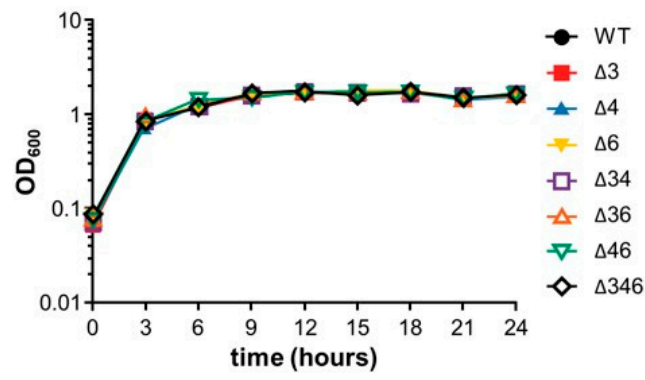

C.

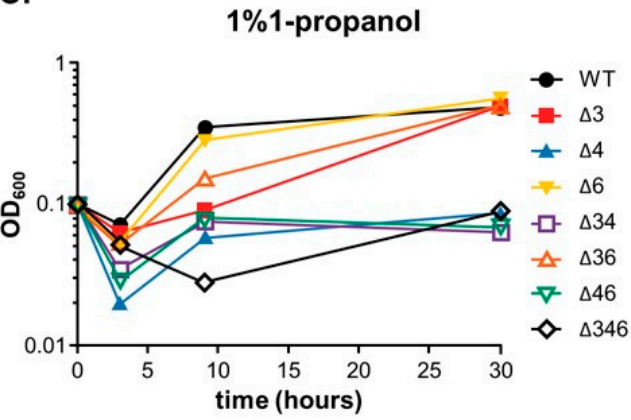

B.

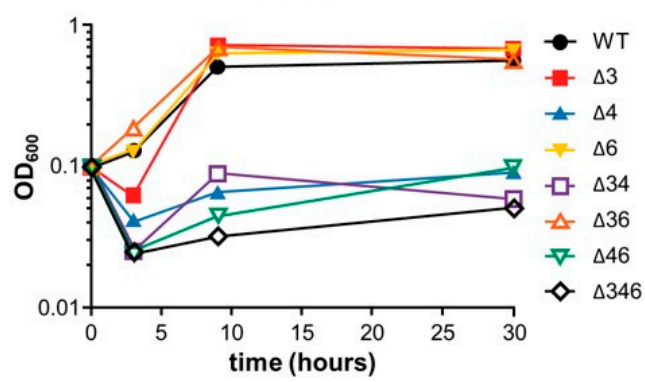

D.

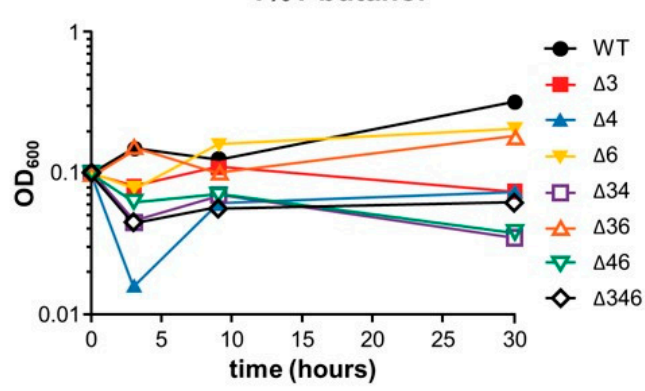

Figure 3. Growth rates of wild-type (WT) or mutant strains in different medium. (A) Growth rates in LB medium. (B) Growth rates in M9 medium containing 1\% ethanol. (C) Growth rates in M9 medium containing 1\% 1-propanol.

(D) Growth rates in M9 medium containing 1\% 1-butanol. 


\subsection{Gene Expression Patterns of Wild-Type and Mutant Strains in the Presence of Ethanol}

Gene expression patterns of wild-type and mutant strains cultivated in $5 \mathrm{mM}$ citrate medium or $5 \mathrm{mM}$ citrate medium with $0.5 \%$ ethanol were compared through transcript analysis, with the gyrase gene (A4U85_RS04125) as a control to calculate relative expression levels (Figure 4). In the wild-type strain, it can be seen that genes encoding FeADHs were more highly expressed than the other Adh genes, with the exception of Adh5 (Figure 4A). Expression levels of $A d h 3$ and Adh6 did not change in the presence of ethanol, but Adh4 expression significantly increased by 3.79 - to 9.39 -fold $(p<0.001)$ in the ethanol-containing medium (Figure 4A). In mutant strains, genes encoding FeADHs were also more highly expressed than the other $A d h$ genes, with the exception of $A d h 5$ (Figure 4B-H). In the $\Delta 3$ (Figure 4B), $\Delta 6$ (Figure 4D), and $\Delta 36$ (Figure 4F) mutant strains, Adh4 expression also significantly increased in the presence of ethanol $(p<0.01)$. These results suggest that ADH4 plays a significant role in ethanol metabolism, while ADH3, ADH5, and ADH6 may have other key functions that necessitate a high level of expression, regardless of the presence of ethanol.

A.

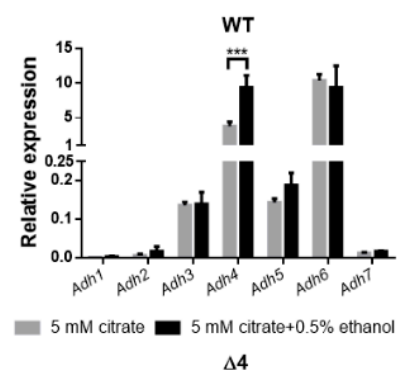

C.

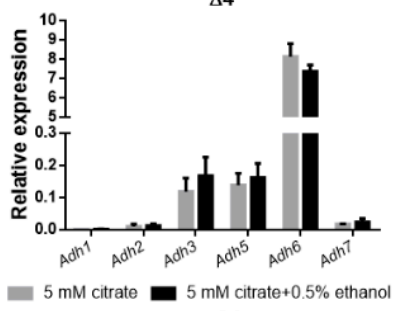

E.

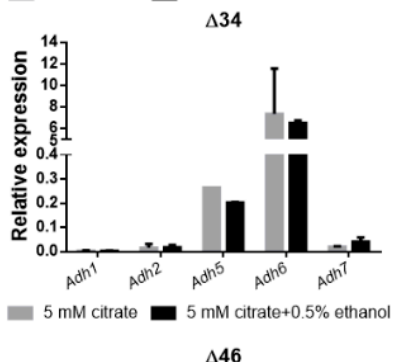

G.

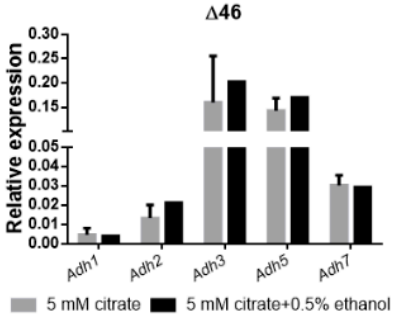

B.

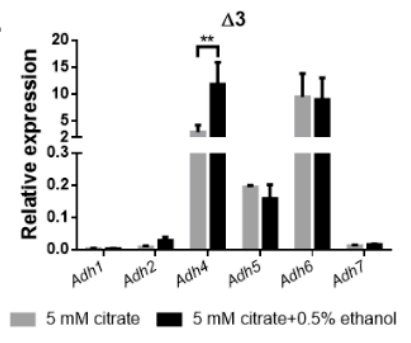

D.

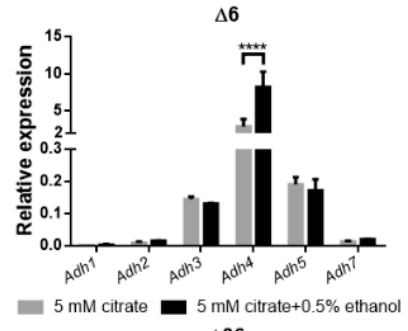

F.
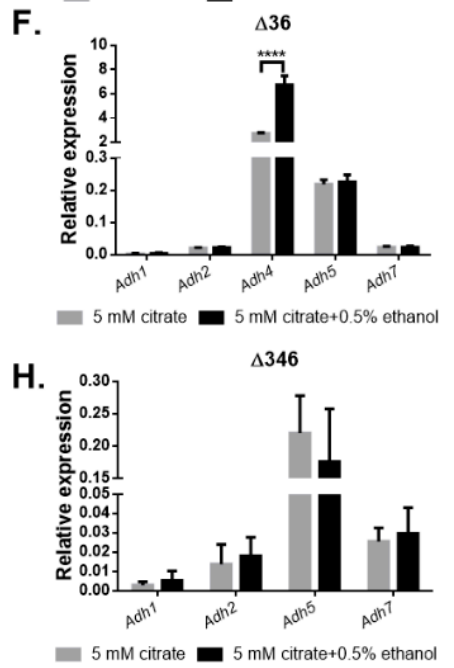

Figure 4. Relative gene expression of $A d h$ genes in wild-type and mutant strains after culturing in medium with or without ethanol. The gyrase gene (A4U85_RS04125) was used as a control to calculate relative expression levels. Comparison of relative gene expression for A. baumannii ATCC 19606 (A) wild-type; (B) $\Delta 3$ single mutant; (C) $\Delta 4$ single mutant; (D) $\Delta 6$ single mutant; (E) $\Delta 34$ double mutant; (F) $\Delta 36$ double mutant; (G) $\Delta 46$ double mutant; and (H) $\Delta 346$ triple mutant strains cultured in M9 medium with $5 \mathrm{mM}$ citrate (gray bar) or $5 \mathrm{mM}$ citrate and $0.5 \%$ ethanol (black bar). Two-way ANOVA tests were conducted to assess statistical significance. ${ }^{* *} p<0.01$; ${ }^{* * *} p<0.001 ; * * * * p<0.0001$. 


\subsection{Adh3 and Adh6 Are Involved in Inorganic and Organic Oxidative Stress Responses}

Previous research has suggested that AdhA in Synechocystis sp. PCC 6803 may help to increase ethanol tolerance by maintaining an adequate level of NADH or NADPH to counteract oxidative stress [16], and thus we considered the possibility that FeADHs may similarly act to counterbalance oxidative stress by maintaining the homeostasis of NADH or NADPH in A. baumannii cells. We accordingly cultured wild-type and mutant strains in LB medium with an initial $\mathrm{OD}_{600}$ of 0.1 . Viable bacterial counts were determined when the $\mathrm{OD}_{600}$ reached 0.6, after which cultures were treated with $5 \mathrm{mM} \mathrm{H}_{2} \mathrm{O}_{2}$ for $20 \mathrm{~min}$. Viable bacterial counts were again assessed, and survival rates were then determined by comparing with pre-testing viability counts (Figure 5). The results showed that only the $\Delta 4$ single mutant and the $\Delta 46$ double mutant maintained comparable survival rates after $\mathrm{H}_{2} \mathrm{O}_{2}$ treatment (Figure 5A), indicating a critical role for ADH3 in countering inorganic oxidative stress. The same experiment was performed again, but $300 \mu \mathrm{M}$ of organic tert-BHP was applied for $20 \mathrm{~min}$ instead of $\mathrm{H}_{2} \mathrm{O}_{2}$. The results showed that all mutants experienced significant reductions of at least $30 \%$ in viability as compared to wild-type, and this suggests that all three FeADHs may contribute to organic hydroperoxide resistance (Figure 5B).
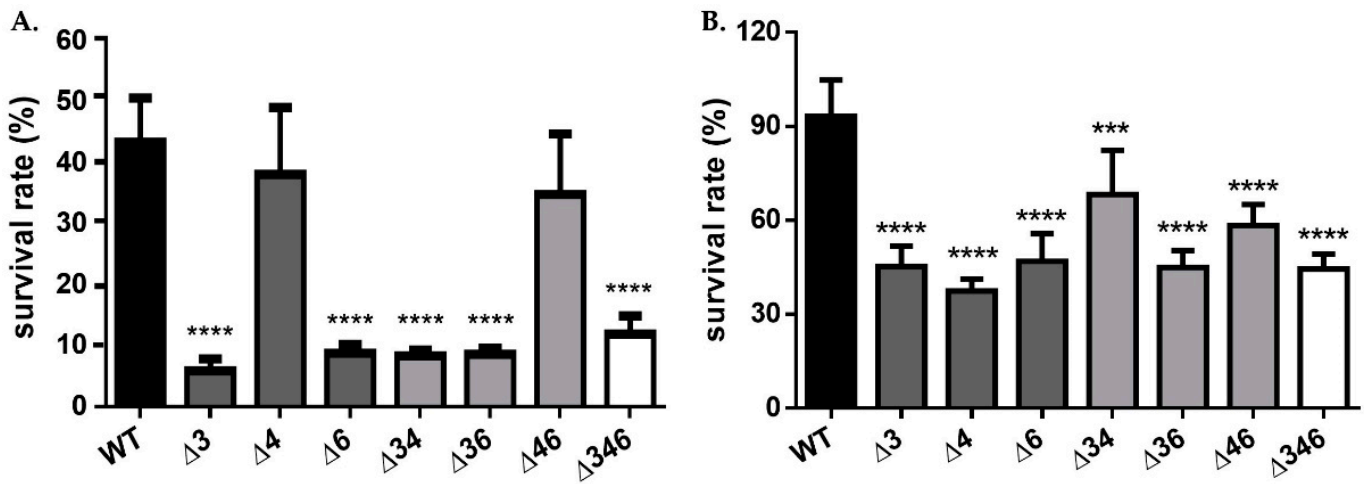

Figure 5. Survival rates of wild-type or mutant strains treated with (A) $5 \mathrm{mM} \mathrm{H}_{2} \mathrm{O}_{2}$; or (B) $300 \mathrm{mM}$ tert-BHP for 20 min. Two-way ANOVA tests were conducted to assess statistical significance. ${ }^{* *} p<0.001 ; * * * * 0.0001$.

Cultures were collected for RNA extraction, and differential gene expression under inorganic and organic oxidative stress was analyzed using qRT-PCR. The results showed that no $A d h$ genes were upregulated in the wild-type strain after $\mathrm{H}_{2} \mathrm{O}_{2}$ treatment; in fact, expression levels of $A d h 4$ and $A d h 6$ decreased significantly (Figure 6A). However, after $\mathrm{H}_{2} \mathrm{O}_{2}$ treatment, Adh 6 expression increased significantly in the $\Delta 34$ double mutant strain (Figure 6E); Adh 3 and Adh 5 expression increased significantly in the $\Delta 46$ double mutant strain (Figure 6G), and $A d h 5$ expression increased significantly in the $\Delta 346$ triple mutant strain (Figure $6 \mathrm{H}$ ). These findings suggest that $A d h 5$ may partially complement inorganic oxidative stress responses when $A d h 3$ and $A d h 6$ are not available. Following tert-BHP treatment, no $A d h$ genes were upregulated in the wild-type strain (Figure 7A), but $A d h 6$ expression increased significantly in $\Delta 3$ single mutant (Figure $7 \mathrm{~B}$ ) and $\Delta 4$ single mutant (Figure 7C) strains. Adh3 expression increased significantly in the $\Delta 46$ double mutant (Figure 7G), while $A d h 5$ expression also significantly rose in both the $\Delta 46$ double mutant (Figure $7 \mathrm{G}$ ) and $\Delta 346$ triple mutant strains (Figure $7 \mathrm{H}$ ), presumably to complement the stress response in the absence of $A d h 6$ and $A d h 3$. Taken together, these results point to a critical role for $A d h 3$ and $A d h 6$ in countering inorganic and organic oxidative stress. 
A.

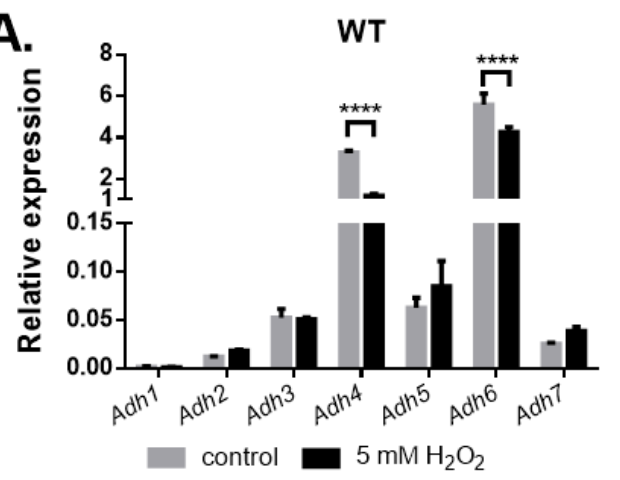

C.

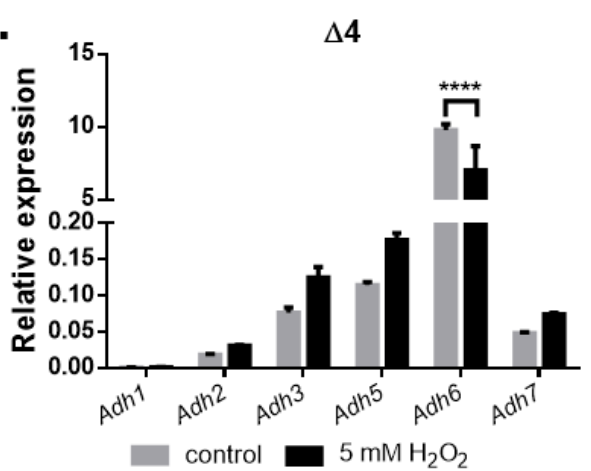

E.

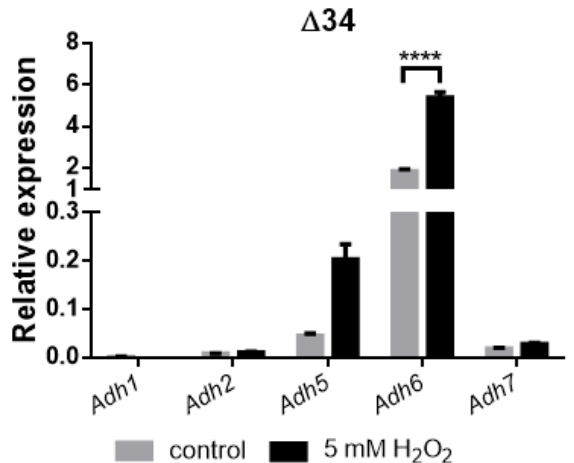

G.

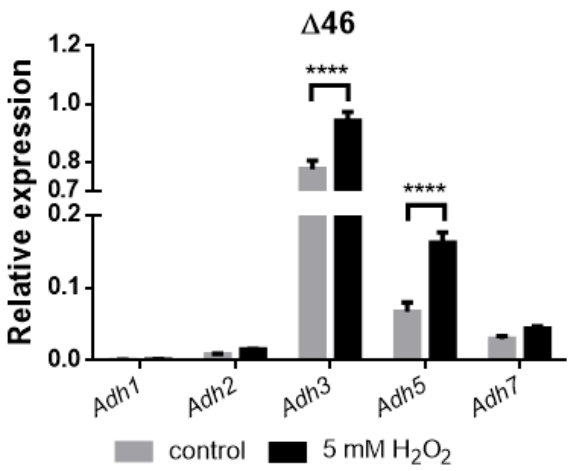

B.

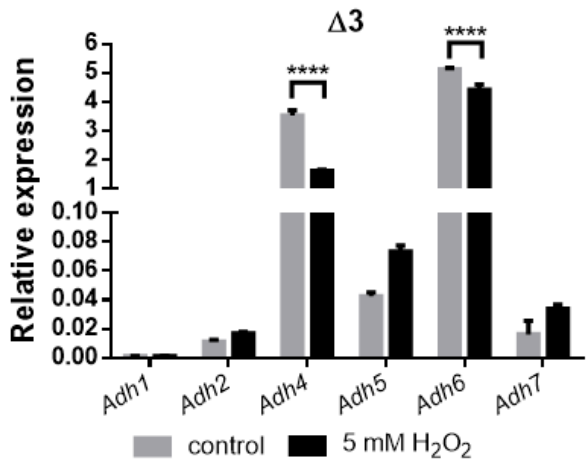

D.

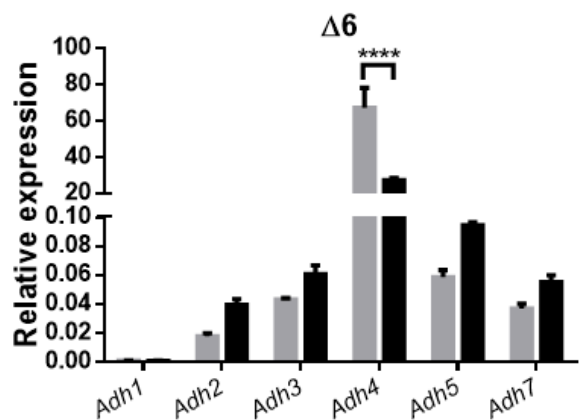

F.

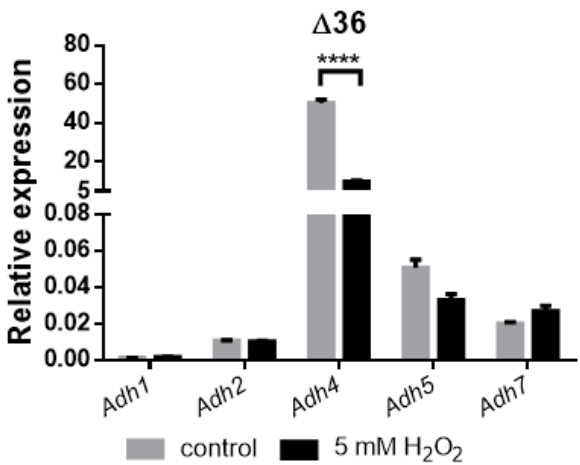

H.

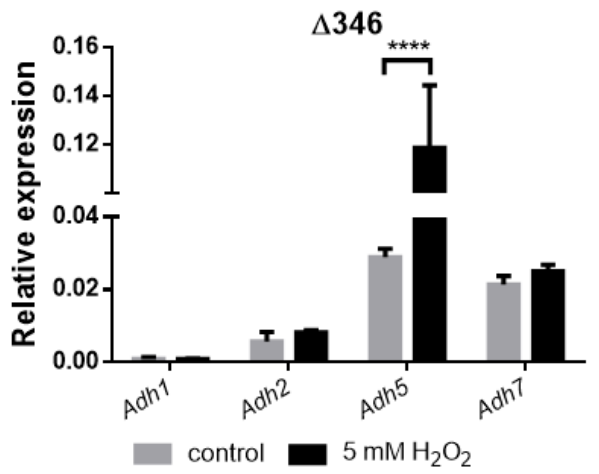

Figure 6. Relative gene expression of $A d h$ genes in wild-type and mutant strains after treatment with $\mathrm{H}_{2} \mathrm{O}_{2}$ for 20 min. Comparison of relative gene expression for A. baumannii ATCC 19606 (A) wild-type; (B) $\Delta 3$ single mutant; (C) $\Delta 4$ single mutant; (D) $\Delta 6$ single mutant; (E) $\Delta 34$ double mutant; (F) $\Delta 36$ double mutant; (G) $\Delta 46$ double mutant; and (H) $\Delta 346$ triple mutant strains cultured in M9 medium before (gray bar) and after $5 \mathrm{mM} \mathrm{H}_{2} \mathrm{O}_{2}$ treatment for 20 min (black bar). Two-way ANOVA tests were conducted to assess statistical significance. ${ }^{* * *} p<0.0001$. 
A.

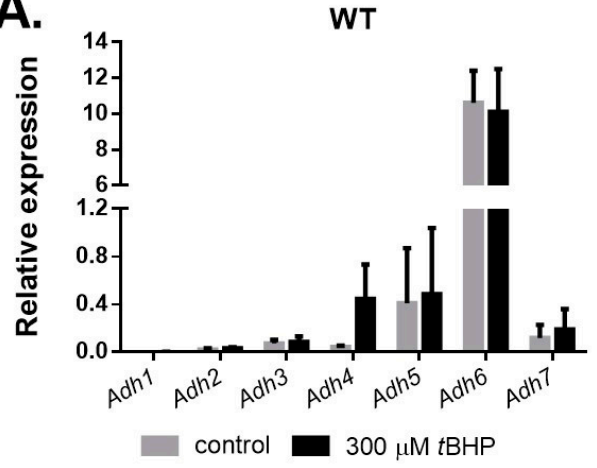

C.

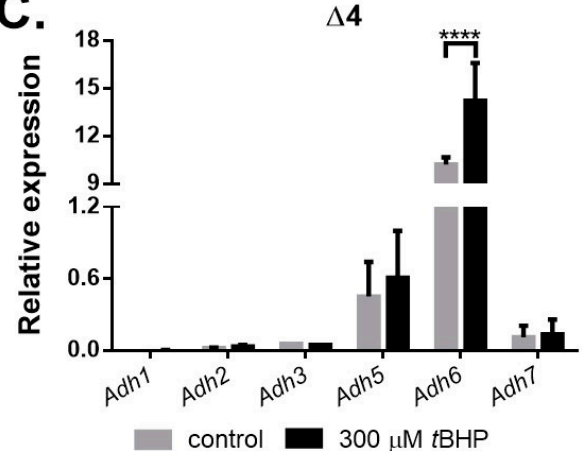

E.

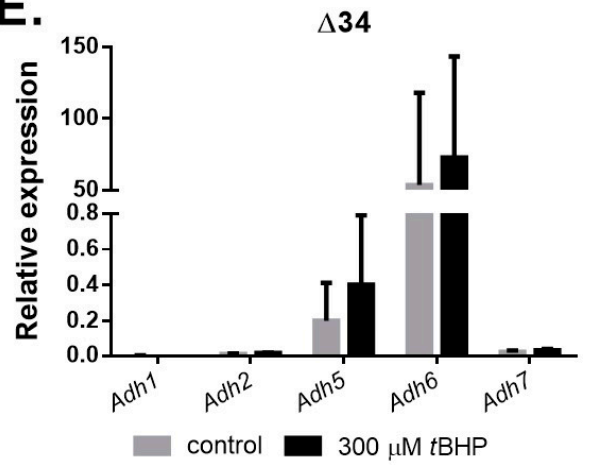

G.

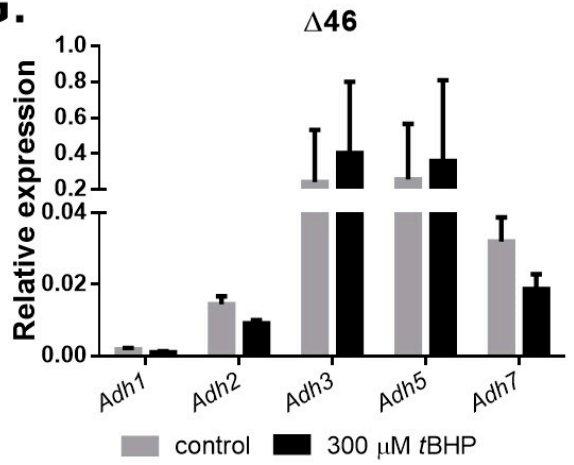

B.

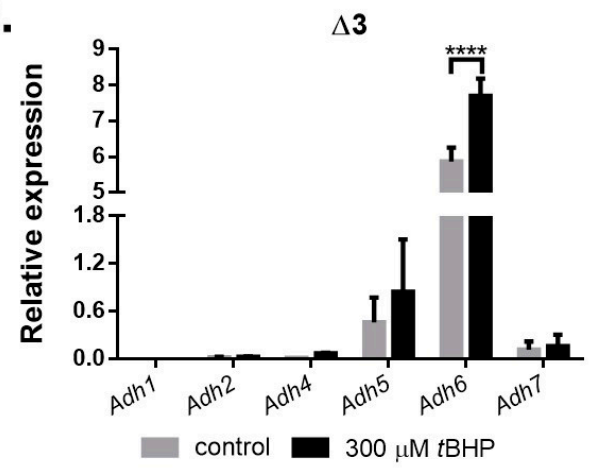

D.

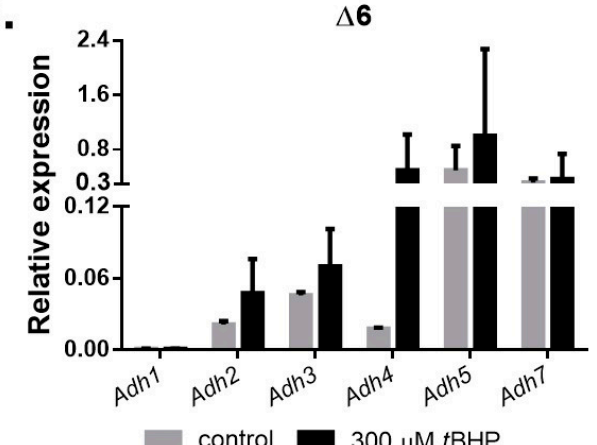

F.

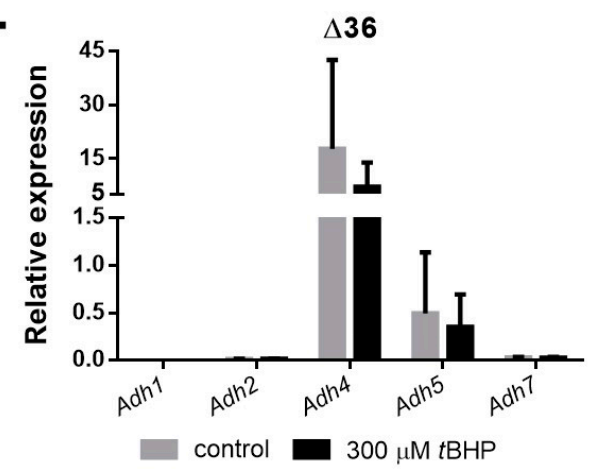

H.

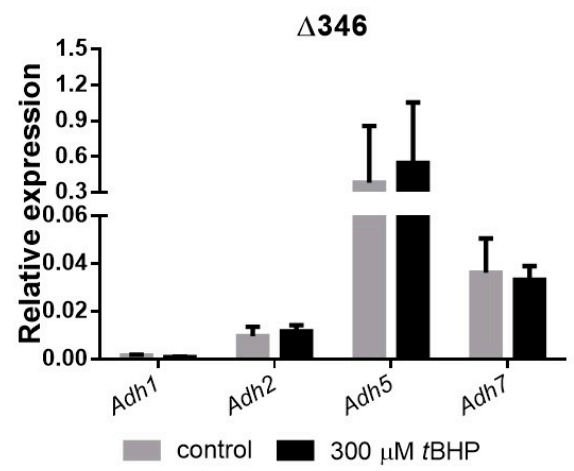

Figure 7. Relative gene expression of Adh genes in wild-type and mutant strains after treatment with tert-BHP for 20 min. Comparison of relative gene expression for A. baumannii ATCC 19606 (A) wild-type; (B) $\Delta 3$ single mutant; (C) $\Delta 4$ single mutant; (D) $\Delta 6$ single mutant; (E) $\Delta 34$ double mutant; (F) $\Delta 36$ double mutant; (G) $\Delta 46$ double mutant; and (H) $\Delta 346$ triple mutant strains cultured in M9 medium before (gray bar) and after $300 \mathrm{mM}$ tert-BHP treatment for 20 min (black bar). Two-way ANOVA tests were conducted to assess statistical significance. ${ }^{* * * *} p<0.0001$. 


\subsection{The Adh3 Stress Resistance Response Does Not Disrupt Homeostasis of Cytosolic $\mathrm{NADH} / \mathrm{NAD}^{+}$}

To ascertain if any ADHs were involved in $\mathrm{NADH} / \mathrm{NAD}^{+}$homeostasis, the plasmid pWH1266-peredox-mCherry, containing a Peredox cassette, was transformed into wildtype and mutant strains for qualitative and quantitative fluorescence analysis. When transformed strains were treated with $5 \mathrm{mM} \mathrm{H}_{2} \mathrm{O}_{2}$ for $20 \mathrm{~min}$, the intensity of mCherry fluorescence was reduced in both wild-type (Figure 8A) and $\Delta 3$ single mutant (Figure 8B) strains, indicative of reduced bacterial viability. However, the intensity of T-Sapphire fluorescence in both strains was unaffected by $\mathrm{H}_{2} \mathrm{O}_{2}$ treatment (Figure 8), and this indicates that the oxidative stress response mediated by ADHs does not impact the homeostasis of cytosolic NADH/ NAD ${ }^{+}$.

A.
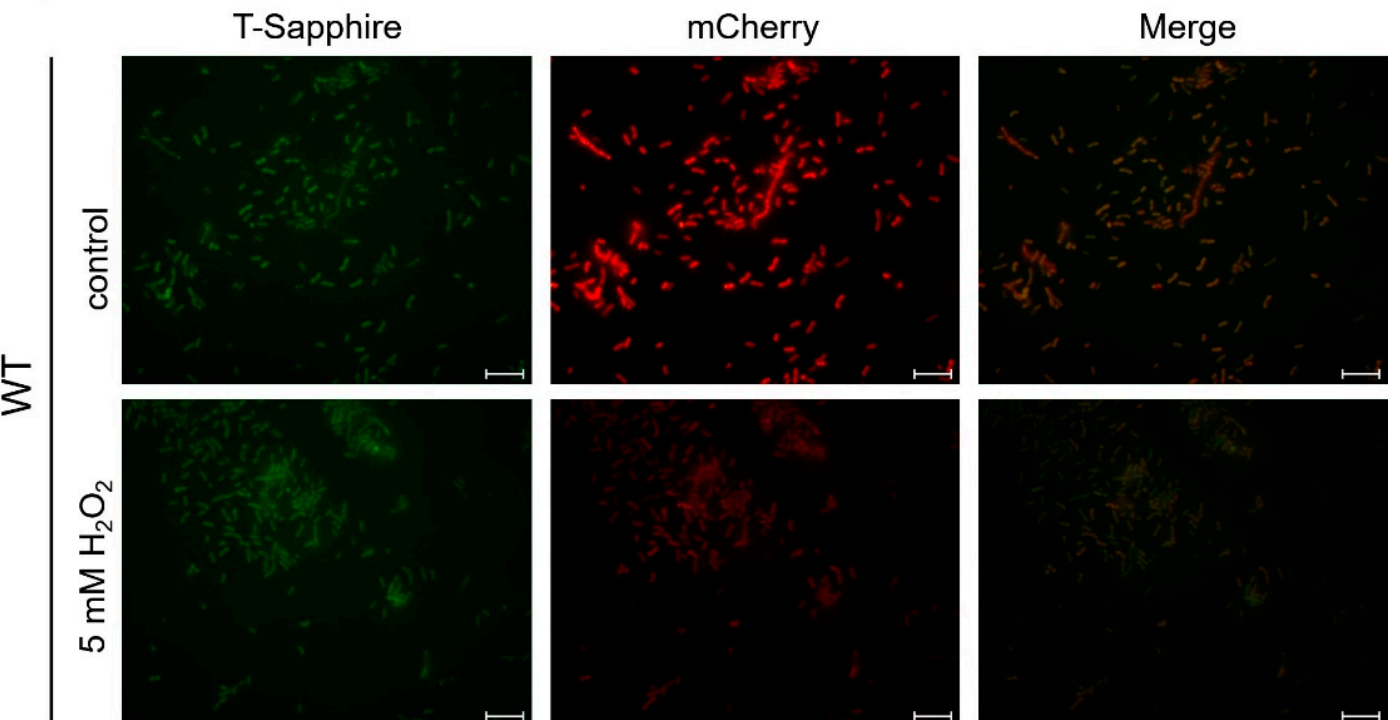

B.
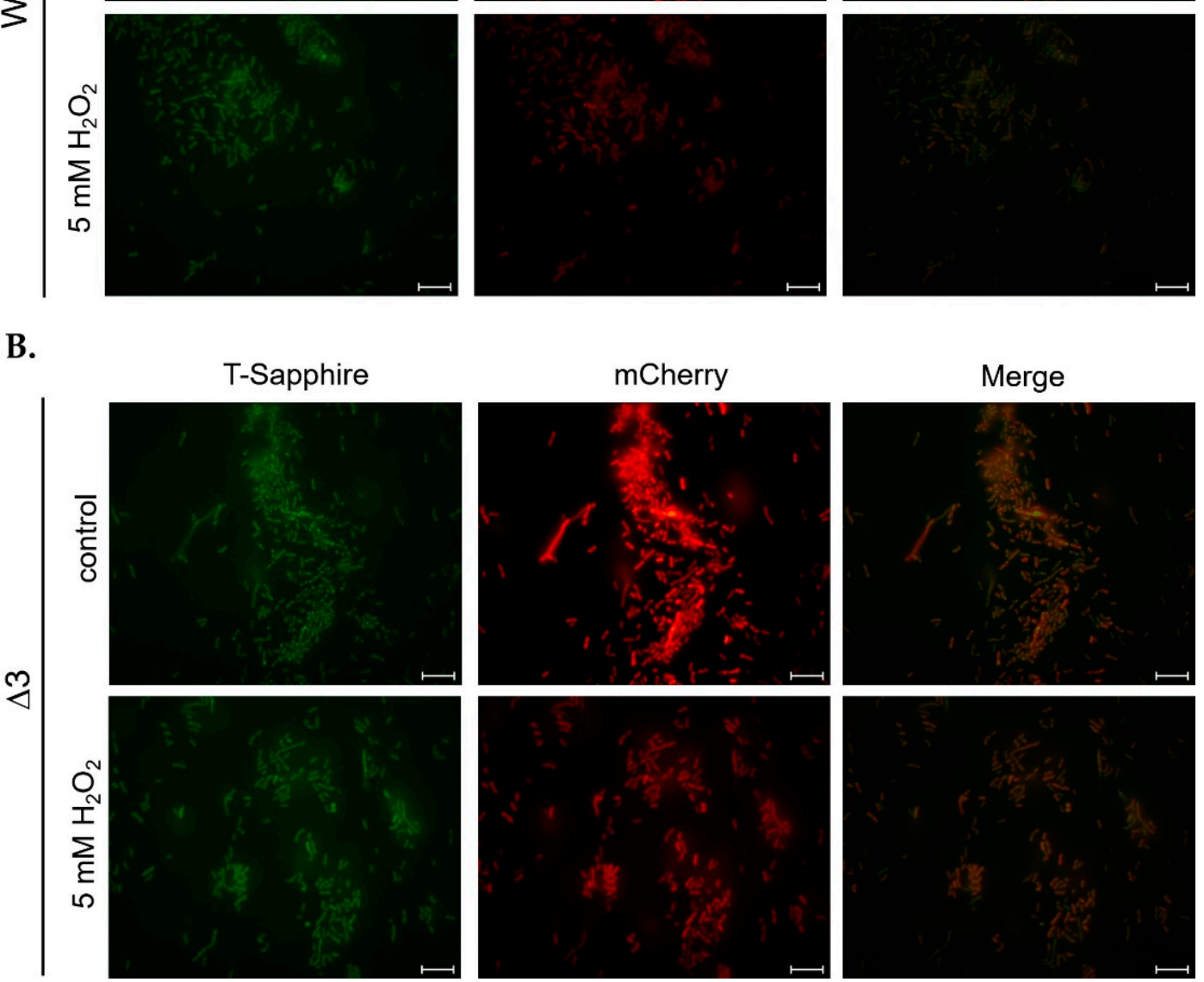

Figure 8. Fluorescence analysis of A. baumannii ATCC 19606 (A) wild-type and (B) $\Delta 3$ single mutant with a Peredox plasmid. Here, $\mathrm{mCherry}$ fluorescence reflects bacterial viability, while T-Sapphire fluorescence reflects redox changes in bacteria. A total of $5 \mu \mathrm{L}$ of bacterial culture before (control) and after $5 \mathrm{mM} \mathrm{H}_{2} \mathrm{O}_{2}$ treatment for 20 min were added to slides before observation, with mCherry images captured after $4 \mathrm{~s}$ of excitation at a wavelength of $587 \mathrm{~nm}$, while T-Sapphire images were captured after $8 \mathrm{~s}$ of excitation at a wavelength of $400 \mathrm{~nm}$. Scale bars: $10 \mu \mathrm{m}$. 


\subsection{Adh3 and Adh6 Are Associated with Virulence against G. mellonella}

Correlations between higher stress resistance and higher virulence have previously been reported for A. baumannii [17], and we sought to ascertain if ADHs were involved in virulence, using a common model organism, G. mellonella $[15,18,19]$. We injected $5 \times 10^{6}$ CFU of wild-type and mutant strains into sets of $10 \mathrm{G}$. mellonella larvae, with PBS and heat-treated A. baumannii serving as controls (Figure 9). Kaplan-Meier survival curves showed that all 10 larvae injected with wild-type or $\Delta 4$ single mutant strains died within $24 \mathrm{~h}$ of injection, while all 10 PBS-injected larvae remained alive at $120 \mathrm{~h}$ post-injection (Figure 9A). Larvae injected with heat-treated A. baumannii experienced $70 \%$ less mortality at $120 \mathrm{~h}$ post-injection, and reduced mortality was also observed for the $\Delta 36$ double mutant, $\Delta 34$ double mutant, and $\Delta 6$ single mutant strains, which maintained $>50 \%$ survival rates at $120 \mathrm{~h}$ post-injection (Figure 9A). Larvae injected with the $\Delta 346$ triple mutant strain also maintained a $40 \%$ survival rate at $120 \mathrm{~h}$ post-injection (Figure $9 \mathrm{~A}$ ). These results suggest that $A d h 3$ and $A d h 6$ likely contribute to virulence against G. mellonella. We also examined the melanization of G. mellonella larvae after injection, as this process is a key part of the insect response to bacterial infection, with melanin aggregation observable around microbes within the hemolymph. This is believed to promote pathogen killing. Melanization status was scored daily as shown in Figure 9C, with larvae that are white in color throughout the body scored as 0 , those with dark spots on the head and tail scored as 1 , those with dark lines appearing on the body scored as 2 , those with dark lines across the entire body scored as 3 , and those that appear fully darkened scored as 4 . The highest melanization scores were observed in larvae injected with wild-type or $\Delta 4$ single mutant strains, in accordance with the survival results. However, larvae injected with other mutant strains exhibited similar levels of melanization as heat-treated A. baumannii (Figure 9B).

A.

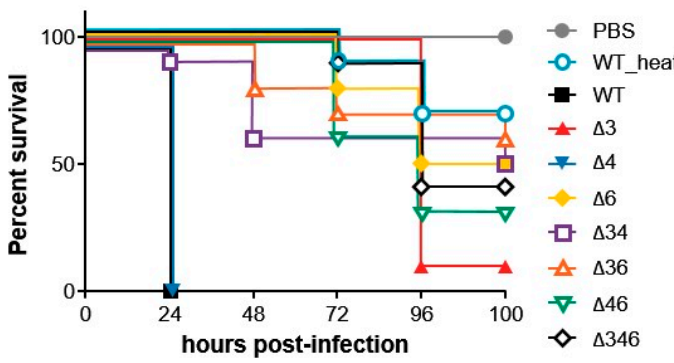

B.

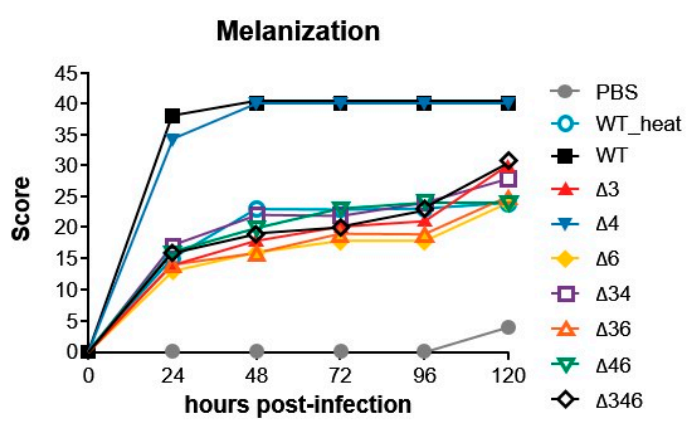

C.

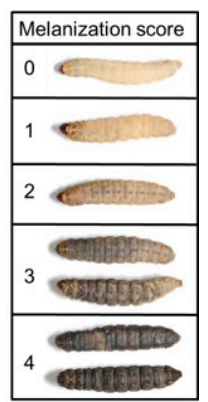

Figure 9. G. mellonella survival rates and melanization scores after infection with A. baumannii ATCC 19606 wild-type (WT) and mutant strains. (A) Kaplan-Meier survival curves, with each curve representing a single experiment performed with 10 larvae. (B) Melanization score curves. (C) Pictorial definition of melanization scores for reference. Larvae were infected with $5 \times 10^{6} \mathrm{CFU}$ of wild-type or mutant strains, with PBS used as the buffer and serving as a control. WT_heat indicates wild-type $A$. baumannii treated at $100^{\circ} \mathrm{C}$ for $10 \mathrm{~min}$. 


\section{Discussion}

In this study, we identified seven annotated Adh genes in A. baumannii ATCC 19606 following a search of GenBank, and further examined the roles of three FeADHs: ADH3, $\mathrm{ADH} 4$, and ADH6. We found that ADH4 played a key role in ethanol metabolism, as observed from substrate specificity assays (Table 1), viability assays in alcohol-containing medium (Figure 3), and gene expression patterns in the presence of ethanol (Figure 4); while $\mathrm{ADH} 3$ and $\mathrm{ADH} 6$ were mainly involved in the oxidative stress response and were associated with virulence, as seen in the results of oxidative stress assays (Figure 5), gene expression patterns in the presence of inorganic and organic hydroperoxides (Figures 6 and 7), and G. mellonella virulence assays (Figure 9). The results suggest that ADHs may play a broad role in A. baumannii beyond ethanol metabolism, and regarding issues such as the potential role of ADH5 in complementing the oxidative stress response in the absence of $\mathrm{ADH} 3$ and ADH6 expression, the relatively low number of Adh genes annotated thus far in terms of the genome size of A. baumannii, and the roles of other non-iron-containing ADHs, further research is warranted.

Genomic and proteomic analysis of the three FeADHs examined in this study showed that the GGGS cofactor binding site motif (GGGSXXD) was conserved in all FeADHs [1,8], and four key iron-binding sites $(\mathrm{D}, \mathrm{H}, \mathrm{H}, \mathrm{H})$ and a key aspartic acid residue (D; located at position 39 in $\mathrm{ADH} 3$, position 46 in $\mathrm{ADH} 4$, and position 41 in $\mathrm{ADH} 6$ ) were also found in all three FeADHs (Figure 1B). The aspartic acid residue shows a preference for $\mathrm{NAD}^{+}$ as the cofactor, as this residue is replaced with glycine $(G)$ in some FeADHs in other microorganisms [20,21], resulting in a shift to $\mathrm{NADP}^{+}$as the preferred cofactor $[22,23]$. It has been suggested that the shorter side chain of glycine allows more space for the phosphate of $\mathrm{NADP}^{+}[1]$, while aspartic acid has a longer side chain that only allows space for $\mathrm{NAD}^{+}$binding [24].

We found that $A$. baumannii was able to survive in medium containing only ethanol, 1-propanol, or 1-butanol as the sole energy source (Figure 3), and although ADH4 had higher affinity for ethanol (Table 1), enzymatic activity against 1-propanol and 1-butanol was also detected. This is consistent with findings for ADHs in other microorganisms, which typically have activity against most aliphatic alcohols $[23,25,26]$, although some substrates may be preferred over others; however, there are also ADHs that have strong specificity for a particular alcohol $[27,28]$. A diverse range of enzymatic activity enables $A$. baumannii to survive under challenging conditions, make use of various energy sources, and demonstrate greater stress resilience overall.

Oxidative stress assays (Figure 5) and gene expression patterns in the presence of inorganic (Figure 6) and organic (Figure 7) hydroperoxides indicate that ADH3 and ADH6 have critical roles in the oxidative stress response, and this has been observed for ADHs in other microorganisms as well $[10,16,29]$, some of which are also involved in the stress response to heat and other stressors [10,29]. ADHs have also been reported to be involved in bacterial biofilm formation [11], and Adh expression was shown to be upregulated in A. baumannii ATCC 17978 strains grown under biofilm conditions [11]. Biofilm formation can increase stress tolerance, but the exact role of ADHs in biofilm formation is unclear as yet. A recent study has shown that $A$. baumannii $\mathrm{ADH}$ may be involved in quorum sensing during biofilm formation, and the inhibition of $\mathrm{ADH}$ also reduced the expression of quorum sensing-related signalling [11]. However, it remains unclear whether ADH is driving the quorum sensing process, or merely acting as a feedback modulator; moreover, other functions of $\mathrm{ADH}$ during stress resistance and biofilm formation cannot be ruled out at present. Still, the results show that ADHs are critical to A. baumannii survival under oxidative stress conditions or in the presence of alcohol substrates, and it is possible that ADHs can serve as targets for the development of novel antiseptic or antibiotic strategies.

Previous research has shown that A. baumannii ATCC 17978 cells cultured in ethanolcontaining medium subsequently demonstrated increased virulence against $G$. mellonella larvae [15], and the authors speculated that this virulence may be driven by increased production of indole acetic acid (IAA) during ethanol exposure by A. baumannii. If this 
is confirmed, it would be quite concerning, as ethanol-based disinfectants are routinely used in clinical settings. However, it is possible that this virulence may in fact be driven by increased $A d h$ gene expression in response to oxidative stress induced by peroxidebased disinfectants or bleach, which are more widely applied in hospital environments and also persist longer on surfaces than volatile ethanol. Previous studies have found that the AdhE gene, which encodes a dual-function acetaldehyde-CoA and alcohol dehydrogenase, was upregulated in Streptococcus pneumoniae cultured in the presence of ethanol and subjected to oxidative stress, and this resulted in increased virulence against murine RAW 264.7 cells [12]; interestingly, $\triangle A d h E$ mutant strains demonstrated reduced pathogenicity and virulence [12], and this was also observed in E. coli O157:H7 [30]. In this study, we found that $A d h 3$ and $A d h 6$ were upregulated in response to oxidative stress (Figures 6 and 7), and $\triangle A d h 3$ and $\triangle A d h 6$ mutant strains exhibited less virulence against $G$. mellonella larvae (Figure 9). Further research to elucidate the underlying mechanisms, as well as field studies to assess Adh3 and Adh6 expression in A. baumannii samples collected from clinical settings, could help to validate this association.

In conclusion, this study shows that FeADHs have diverse functions in A. baumannii beyond ethanol metabolism, being involved in oxidative stress responses and virulence, but different ADHs have varying primary functions. Further research into the additional functions of FeADHs in A. baumannii, as well as the roles of other ADHs, is warranted.

\section{Materials and Methods}

\subsection{Bacterial Strains, Plasmids, and Primers}

A. baumannii ATCC 19606 and Escherichia coli strains were cultured in LB medium at $37^{\circ} \mathrm{C}$ with shaking, and solid cultures were grown on LB medium containing $1.5 \%$ agar. Mutant $A$. baumannii strains were grown in $\mathrm{M} 9$ media $\left(33.7 \mathrm{mM} \mathrm{Na}_{2} \mathrm{HPO}_{4}, 22 \mathrm{mM} \mathrm{KH} \mathrm{PO}_{4}\right.$, $8.55 \mathrm{mM} \mathrm{NaCl}, 9.35 \mathrm{mM} \mathrm{NH}_{4} \mathrm{Cl}, 1 \mathrm{mM} \mathrm{MgSO}_{4}, 0.3 \mathrm{mM} \mathrm{CaCl}_{2}$ ), a minimal microbial growth media to which $1 \%$ ethanol, $1 \%$ 1-propanol, $1 \%$ a-butanol, or $5 \mathrm{mM}$ citrate $(5 \mathrm{mM}$ citrate medium) was added in accordance with experimental needs. The bacterial strains and plasmids used are presented in Table 3. The primers used in this study are presented in Table 2.

Table 3. Plasmids and bacterial strains used in this study.

\begin{tabular}{|c|c|c|c|}
\hline Plasmid & Description & $\begin{array}{c}\text { Antibiotic } \\
\text { Resistance } \\
(\mu \mathrm{g} / \mathrm{mL})\end{array}$ & Reference/Source \\
\hline pK18mobsacB & Suicide vector for homologous recombination & Kan50 & [31] \\
\hline pK18 18 Adh1 & $\begin{array}{l}\text { pK18mobsacB contains the upstream and downstream } \\
\text { regions of } A d h 1\end{array}$ & Kan50 & This study \\
\hline pK18 $\triangle A d h 2$ & $\begin{array}{l}\text { pK18mobsacB contains the upstream and downstream } \\
\text { regions of } A d h 2\end{array}$ & Kan50 & This study \\
\hline pK18 18 Adh3 & $\begin{array}{l}\text { pK18mobsacB contains the upstream and downstream } \\
\text { regions of } A d h 3\end{array}$ & Kan50 & This study \\
\hline $\mathrm{pK} 18 \Delta$ Adh4 & $\begin{array}{l}\text { pK18mobsacB contains the upstream and downstream } \\
\text { regions of } A d h 4\end{array}$ & Kan50 & This study \\
\hline pK18 $\Delta A d h 5$ & $\begin{array}{c}\text { pK18mobsacB contains the upstream and downstream } \\
\text { regions of } A d h 5\end{array}$ & Kan50 & This study \\
\hline $\mathrm{pK} 18 \Delta$ Adh6 & $\begin{array}{l}\text { pK18mobsacB contains the upstream and downstream } \\
\text { regions of } A d h 6\end{array}$ & Kan50 & This study \\
\hline pK18 $\triangle A d h 7$ & $\begin{array}{l}\text { pK18mobsacB contains the upstream and downstream } \\
\text { regions of } A d h 7\end{array}$ & Kan50 & This study \\
\hline pQE80L & $\begin{array}{l}\text { Expression vector with colE1 origin for His-tag fusion } \\
\text { protein purification }\end{array}$ & Amp50 & Qiagen \\
\hline $\mathrm{p} A d h 3$ & $\mathrm{Ap}^{\mathrm{r}}$; Adh3 cloned into BamHI-HindIII sites of pQE80L & Amp50 & This study \\
\hline pAdh4 & $\mathrm{Ap}^{\mathrm{r}}$; Adh4 cloned into BamHI-HindIII sites of pQE80L & Amp50 & This study \\
\hline pAdh6 & $\mathrm{Ap}^{\mathrm{r}}$; Adh6 cloned into BamHI-SmaI sites of pQE80L & Amp50 & This study \\
\hline
\end{tabular}


Table 3. Cont.

\begin{tabular}{|c|c|c|c|}
\hline Plasmid & Description & $\begin{array}{c}\text { Antibiotic } \\
\text { Resistance } \\
(\mu \mathrm{g} / \mathrm{mL})\end{array}$ & Reference/Source \\
\hline pWH1266 & $\begin{array}{l}\mathrm{Ap}^{\mathrm{r}} ; \mathrm{Tc}^{\mathrm{r}} \text {; shuttle vector for E. coli and A. baumannii } \\
\mathrm{Ap}^{\mathrm{r}} \text {; fluorescent biosensor of the cytosolic }\end{array}$ & Amp50, Tc12.5 & [32] \\
\hline $\begin{array}{l}\text { pRsetB-His7tag- } \\
\text { Peredox-mCherry }\end{array}$ & $\begin{array}{l}\text { NADH/NAD }{ }^{+} \text {redox state by combining a circularly } \\
\text { permuted GFP T-Sapphire with a bacterial } \\
\text { NADH-binding protein, Rex, and the red fluorescence of } \\
\text { a tandemly attached mCherry. }\end{array}$ & Amp50 & {$[33,34]$} \\
\hline $\begin{array}{c}\text { pWH1266_peredox- } \\
\text { mCherry }\end{array}$ & $\begin{array}{c}\mathrm{Ap}^{\mathrm{r}} ; \mathrm{Tc}^{\mathrm{r}} ; \text { permuted GFP T-Sapphire with a bacterial } \\
\text { NADH-binding protein, Rex, and the red fluorescence of } \\
\text { a tandemly attached mCherry from pRsetB-His7tag- } \\
\text { Peredox-mCherry was cloned into EcoRI sites of } \\
\text { pWH1266 }\end{array}$ & Amp50, Tc12.5 & This study \\
\hline Strain & \multicolumn{2}{|l|}{ Description } & Reference/Source \\
\hline E. coli $\mathrm{DH} 5 \alpha$ & \multicolumn{2}{|c|}{$\mathrm{F}^{-}, \sup E 44$, hsdR17, rec $A 1$, gyr $A 96$, end $A 1$, thi- 1, relA1, deoR, $\lambda^{-}$} & ATCC53868 \\
\hline $\begin{array}{l}\text { Acinetobacter baumannii } \\
\text { ATCC } 19606\end{array}$ & \multicolumn{2}{|l|}{ Primary strain used in this study } & [31] \\
\hline$\Delta A d h 3(\Delta 3)$ & \multicolumn{2}{|l|}{ Marker-less $A d h 3$ deletion mutant } & This study \\
\hline$\Delta \operatorname{Adh} 4(\Delta 4)$ & \multicolumn{2}{|l|}{ Marker-less Adh4 deletion mutant } & This study \\
\hline$\Delta A d h 6(\Delta 6)$ & \multicolumn{2}{|l|}{ Marker-less Adh6 deletion mutant } & This study \\
\hline$\Delta A d h 34(\Delta 34)$ & \multicolumn{2}{|l|}{ Marker-less Adh34 double deletion mutant } & This study \\
\hline$\Delta A d h 36(\Delta 36)$ & \multicolumn{2}{|l|}{ Marker-less Adh36 double deletion mutant } & This study \\
\hline$\Delta A d h 46(\Delta 46)$ & \multicolumn{2}{|l|}{ Marker-less Adh46 double deletion mutant } & This study \\
\hline$\Delta A d h 346(\Delta 346)$ & \multicolumn{2}{|l|}{ Marker-less Adh346 triple deletion mutant } & This study \\
\hline
\end{tabular}

Amp: ampicillin; Kan: kanamycin.

\subsection{Marker-Less Mutation}

Marker-less mutation was performed as previously described [31], with some minor modifications. Briefly, the adjacent regions of the $A d h$ gene(s) intended for mutation were cloned into plasmid pk18mobsacB, and transformed into $E$. coli $\mathrm{S} 17 \lambda \pi$ to generate a donor strain for conjugation with $A$. baumannii. The E. coli donor strains and $A$. baumannii recipient strains were cultured in LB medium at $37^{\circ} \mathrm{C}$ with shaking for 12 to $16 \mathrm{~h}$, after which a $200 \mu \mathrm{L}$ aliquot of donor bacterial cells was mixed with recipient $A$. baumannii cells at a 1:20 ratio. The mixed cells were spun down and washed with $60 \mu \mathrm{L}$ of conjugation buffer $\left(1 \% \mathrm{NaCl}, 10 \mathrm{mM} \mathrm{MgSO}_{4}\right)$ to remove traces of LB medium, and the cell pellet was resuspended in $60 \mu \mathrm{L}$ of conjugation buffer, then spotted onto a membrane filter $(47 \mathrm{~mm}$ diameter, mixed cellulose esters, A020H047A; Advantech MFS, Dublin, CA, USA) placed on top of $1.5 \%$ LB agar. After cultivation at $37{ }^{\circ} \mathrm{C}$ for $19 \mathrm{~h}$, filters were washed with conjugation buffer to remove bacterial cells, which were spun down and resuspended in $200 \mu \mathrm{L}$ of conjugation buffer, then plated to $1.5 \% \mathrm{LB}$ agar plates containing $50 \mu \mathrm{g} / \mathrm{mL}$ of ampicillin and $50 \mu \mathrm{g} / \mathrm{mL}$ of kanamycin. The first homologous recombination event enables the E. coli donor plasmid, which contains a kanamycin-resistant gene, to be integrated into the bacterial chromosome of $A$. baumannii recipient cells. Successful recombinants were then cultivated in LB medium containing $20 \%$ sucrose but without kanamycin, thus inducing the $A$. baumannii recombinants to excise the $s a c B$ gene in a second crossover event, and thereby enabling the deletion of the target $A d h$ gene(s). Deletion mutants were subsequently confirmed through PCR analysis.

\subsection{Recombinant Alcohol Dehydrogenase Purification and Enzyme Activity Assay}

Protein overexpression and purification methods were adapted from our previous study [31]. Briefly, putative A. baumannii Adh genes were cloned into plasmid pQE80L (Qiagen, Hilden, Germany), which was then transformed into E. coli DH5 $\alpha$ for recombinant protein production. Ni-affinity chromatography was used for recombinant protein 
purification. Columns were charged with $1 \times$ charge buffer $\left(5 \mathrm{mM} \mathrm{NiSO}_{4}\right)$ for $50 \mathrm{~min}$ to enable $\mathrm{Ni}^{2+}$ binding with the column, after which columns were washed with $1 \times$ binding buffer ( $5 \mathrm{mM}$ imidazole, $0.5 \mathrm{M} \mathrm{NaCl}, 20 \mathrm{mM}$ Tris-HCl, $\mathrm{pH}=7.9$ ) for $50 \mathrm{~min}$. Supernatants containing recombinant proteins were then passed through the column, after which the column was washed with $1 \times$ wash buffer $(60 \mathrm{mM}$ imidazole, $0.5 \mathrm{M} \mathrm{NaCl}, 20 \mathrm{mM}$ Tris- $\mathrm{HCl}$, $\mathrm{pH}=7.9$ ), and then bound proteins were eluted using $1 \mathrm{X}$ elute buffer (1 M imidazole, $0.5 \mathrm{M}$ $\mathrm{NaCl}, 20 \mathrm{mM}$ Tris- $\mathrm{HCl}, \mathrm{pH}=7.9$ ). The soluble fraction was collected and passed through Amicon Ultra-15 Centrifugal Filter-10 kDa units (Merck Millipore, Burlington MA, USA) to eliminate proteins smaller than $10 \mathrm{kDA}$. Retained proteins were concentrated by adding $4 \times \mathrm{ADH}$ storage buffer $(320 \mathrm{mM}$ Tris- $\mathrm{HCl}, \mathrm{pH}=7.4,160 \mathrm{mM} \mathrm{KCl})$ to a concentration of $1 \times$ and then centrifuging for $20 \mathrm{~min}$ at $4{ }^{\circ} \mathrm{C}, 4000 \times g$, after which the supernatant was discarded and $1 \times \mathrm{ADH}$ storage buffer was added, followed by centrifugation for $10 \mathrm{~min}$ at $4{ }^{\circ} \mathrm{C}, 4000 \times \mathrm{g}$. Concentrated proteins were divided into aliquots of $250 \mu \mathrm{L}$, to which $250 \mu \mathrm{L}$ of $4 \times \mathrm{ADH}$ storage buffer and $500 \mu \mathrm{L}$ of $100 \%$ glycerol were added, and then divided into $200 \mu \mathrm{L}$ aliquots for storage at $-80^{\circ} \mathrm{C}$. Purified proteins were used in enzymatic assays as previously described [35]. The enzymatic assay reaction contained a final concentration of $80 \mathrm{mM}$ buffer, $2 \mathrm{mM} \mathrm{NAD}{ }^{+}, 1 \mathrm{mM}$ semicarbazide, and $100 \mu \mathrm{L}$ of alcohol (ethanol, 1-propanol, or 1-butanol) in $1 \mathrm{~mL}$. The $\mathrm{OD}_{340}$ for different protein concentrations was determined every $30 \mathrm{~s}$ for three minutes. Specific activity was determined according to the Beer-Lambert Law: $\mathrm{A}_{\lambda}=\varepsilon_{\lambda} \times \mathrm{C} \times 1$, with $\mathrm{A}_{\lambda}$ representing the $\mathrm{OD}_{340}$ difference between the third and the first minutes; $\varepsilon_{\lambda}=6.22 \mathrm{mM}^{-1} \mathrm{~cm}^{-1}$, the coefficient of $\mathrm{OD}_{340}$; and $\mathrm{C}$ indicating the concentration of produced NADH. The production of $1 \mu$ mole of NADH was defined as 1 unit of $\mathrm{ADH}$ activity [36]. Three buffers with different $\mathrm{pH}$ conditions were used: Phosphate buffer ( $\mathrm{PB}$ buffer; $80 \mathrm{mM} \mathrm{Na}_{2} \mathrm{HPO}_{4}, 80 \mathrm{mM} \mathrm{NaH}_{2} \mathrm{PO}_{4}, \mathrm{pH}=5.8-8$ ), Tris- $\mathrm{Cl}$ ( $80 \mathrm{mM}$ Tris- $\mathrm{HCl}, \mathrm{pH}=8-9.5$ ) and carbonate-bicarbonate buffer (CB buffer; $80 \mathrm{mM}$ $\left.\mathrm{Na}_{2} \mathrm{CO}_{3}, 80 \mathrm{mM} \mathrm{NaHCO}_{3}, \mathrm{pH}=9.5-10.1\right)$.

\subsection{Stress Resistance Assays}

Single colonies of each strain were inoculated in $3 \mathrm{~mL}$ LB medium with corresponding antibiotics, which were cultured for $12-16 \mathrm{~h}$ at $37^{\circ} \mathrm{C}$ with agitation. The overnight culture was refreshed with fresh medium to an $\mathrm{OD}_{600}$ of 0.1 . Bacteria were treated with $5 \mathrm{mM}$ $\mathrm{H}_{2} \mathrm{O}_{2}$ or $300 \mu \mathrm{M}$ tert-butyl hydroperoxide (tert-BHP) for $20 \mathrm{~min}$ and $4 \% \mathrm{NaCl}$, and viable counts were then determined by dropping $5 \mu \mathrm{L}$ of cultured medium on LB agar plates 6 times and calculating colony-forming units (CFU) after colonies formed on plates [37].

\subsection{RNA Extraction and $q R T-P C R$}

Bacterial cultures at an $\mathrm{OD}_{600}$ of 0.6 were collected and centrifuged, and pellets were treated with 0.1 volume of fix solution ( $5 \% \mathrm{acid} / \mathrm{phenol}, 95 \%$ ethanol), then centrifuged at $4{ }^{\circ} \mathrm{C}$ at $12,000 \times g$ for $10 \mathrm{~min}$. Bacterial pellets were kept at $-80^{\circ} \mathrm{C}$ before RNA extraction. For RNA extraction, each pellet was suspended in $2 \mathrm{~mL}$ of Nucleozol (REF 740404.200, Macherey-Nagel, Düren, Germany) and processed according to the instruction manual provided by the manufacturer. The concentration of RNA was determined using a NanoDrop 2000c Spectrophotometer (Thermo Fisher Scientific, Waltham, MA, USA). DNA contamination was assessed by conducting PCR analysis on a $2 \mu \mathrm{L}$ RNA sample, using DNA polymerase in the absence of reverse transcriptase. No PCR products were noted, indicating the absence of DNA in purified RNA samples. Following extraction, $2 \mu \mathrm{g}$ of RNA from each sample was prepared for reverse transcription with $1 \times$ RTase buffer, $0.5 \mathrm{mM}$ dNTP, $5 \mathrm{mM}$ DTT, and $200 \mathrm{U}$ of RTase (GScript RTase, MB305-0050, GeneDireX, Taoyuan, Taiwan), and placed at $50^{\circ} \mathrm{C}$ for one hour. Quantitative RT-PCR was performed with $100 \mathrm{ng}$ cDNA for each reaction. SYBR Green (PowerSYBR Green PCR Master Mix, cat no. 4367659, Thermo Fisher Scientific) was mixed with cDNA and the corresponding primers (see Table 2) for PCR in a LightCycler ${ }^{\circledR} 480$ (Roche, Basel, Switzerland) [31].

To ascertain if $A d h$ genes contribute to $\mathrm{NADH} / \mathrm{NAD}^{+}$homeostasis, the Peredox cassette from pRestB-His7tag-peredox-mCherry (Addgene, Watertown MA, USA), a flu- 
orescent biosensor of the cytosolic NADH-NAD ${ }^{+}$redox state [33,34], was inserted at an EcoRI restriction site into the pWH1266 shuttle vector of $A$. baumannii and E. coli, to form pWH1266-pereodox-mCherry. This plasmid was then transferred by electroporation at $1.8 \mathrm{kV}, 200 \mathrm{~W}, 25 \mu \mathrm{F}$ (MicroPulser; Bio-Rad, Hercules, CA, USA) into wild-type and mutant bacterial strains [32] to measure cytosolic NADH:NAD ${ }^{+}$ratios. Following incubation at $37^{\circ} \mathrm{C}$ for one hour, $200 \mu \mathrm{L}$ of bacterial culture was spotted onto $1.5 \% \mathrm{LB}$ agar plates containing $6.25 \mu \mathrm{g} / \mathrm{mL}$ of tetracycline, and plates were subsequently cultured at $37^{\circ} \mathrm{C}$ for 12 to $16 \mathrm{~h}$ to select for successful transformants.

\subsection{Fluorescence Analysis}

Successful transformants harboring the pWH1266_peredox-mCherry plasmid were cultured in LB medium containing $6.25 \mu \mathrm{g} / \mathrm{mL}$ of tetracycline at $37^{\circ} \mathrm{C}$ for 12 to $16 \mathrm{~h}$ until $\mathrm{OD}_{600}=0.3$, after which bacterial cells were concentrated by centrifugation. Cell pellets were resuspended in $300 \mu \mathrm{L}$ of $0.9 \% \mathrm{NaCl}$, from which $50 \mu \mathrm{L}$ of solution was taken and placed on a slide $\left(1^{\prime \prime} \times 3\right.$ " microscope slides; FEA, Taipei, Taiwan), then mounted with a coverslip ( $22 \mathrm{~mm} \times 22 \mathrm{~mm}$; Paul Marienfeld, Lauda-Königshofen, Germany) and sealed around the edges using transparent nail polish. Fixatives were not used in this study. The slides were examined under an Eclipse E800 fluorescent microscope (Nikon, Tokyo, Japan), using red (G-2A filter; Ex 510-560/DM 575/BA 590) and green (B-2A filter; Ex 450-490/DM 505/BA 520) fluorescence filters, and at least three different views were captured for each sample.

\subsection{Virulence Assay with G. mellonella}

A virulence comparison was carried out with A. baumannii ATCC 19606 wild-type and Adh3, Adh4, and Adh6 single, double and triple mutants of each strain. All procedures were performed as previously described, with minor modifications [16]. Ten G. mellonella larvae were selected for the same total weight, and were kept in petri dishes without food prior to infection. Larvae were infected with $5 \times 10^{6} \mathrm{CFU}$ of each strain. Overnight cultures of each strain were washed twice with PBS (0.137 M NaCl, $2.7 \mathrm{mM} \mathrm{KCl,} 10 \mathrm{mM} \mathrm{Na}_{2} \mathrm{HPO}_{4}$, $1.8 \mathrm{mM} \mathrm{KH}_{2} \mathrm{PO}_{4}$ ), then diluted in PBS. Bacteria in $10 \mu \mathrm{L}$ aliquots were injected into the hemocoel of each larva via the last left proleg by a Hamilton syringe. Infected larvae were incubated at $37^{\circ} \mathrm{C}$ and scored for survival (alive/dead) every $24 \mathrm{~h}$. Larvae were also scored for melanization over $96 \mathrm{~h}$, according to a previously described scoring method [38].

\subsection{Statistical Analysis}

Data were analyzed using two-way ANOVA tests, with $p<0.05$ denoting significance.

Supplementary Materials: The following are available online at https:/ /www.mdpi.com/article/10 .3390/ijms22189921/s1.

Author Contributions: Conceptualization, G.-H.L. and H.-Y.S.; methodology, G.-H.L. and H.-Y.S.; formal analysis, M.-C.H. and G.-H.L.; investigation, M.-C.H. and G.-H.L.; resources, G.-H.L.; data curation, M.-C.H. and G.-H.L.; writing-original draft preparation, H.-Y.S. and G.-H.L.; writingreview and editing, G.-H.L. and H.-Y.S.; visualization, M.-C.H. and G.-H.L.; supervision, G.-H.L.; project administration, G.-H.L. and H.-Y.S.; funding acquisition, G.-H.L. All authors have read and agreed to the published version of the manuscript.

Funding: This research was funded by the Buddhist Tzu Chi Medical Foundation, grant number TCMF-SP 110-02. The APC was funded by the Buddhist Tzu Chi Medical Foundation, grant number TCMF-SP 110-02.

Institutional Review Board Statement: Not applicable.

Data Availability Statement: The data presented in this study are available on request from the corresponding author. The data are not publicly available as the full dataset is undergoing analysis to guide future research and potential publications. 
Conflicts of Interest: The authors declare no conflict of interest. The funders had no role in the design of the study; in the collection, analyses, or interpretation of data; in the writing of the manuscript, or in the decision to publish the results.

\section{References}

1. Gaona-López, C.; Julián-Sánchez, A.; Riveros-Rosas, H. Diversity and Evolutionary Analysis of Iron-Containing (Type-III) Alcohol Dehydrogenases in Eukaryotes. PLoS ONE 2016, 11, e0166851. [CrossRef]

2. Horinouchi, T.; Maeda, T.; Furusawa, C. Understanding and engineering alcohol-tolerant bacteria using OMICS technology. World J. Microbiol. Biotechnol. 2018, 34, 157. [CrossRef]

3. Jörnvall, H.; Persson, B.; Jeffery, J. Characteristics of alcohol/polyol dehydrogenases. The zinc-containing long-chain alcohol dehydrogenases. Eur. J. Biochem. 1987, 167, 195-201. [CrossRef] [PubMed]

4. Jörnvall, H. Medium- and short-chain dehydrogenase/reductase gene and protein families: MDR and SDR gene and protein superfamilies. Cell. Mol. Life Sci. 2008, 65, 3873-3878. [CrossRef] [PubMed]

5. Persson, B.; Hedlund, J.; Jörnvall, H. Medium- and short-chain dehydrogenase/reductase gene and protein families: The MDR superfamily. Cell. Mol. Life Sci. 2008, 65, 3879-3894. [CrossRef] [PubMed]

6. Jörnvall, H.; Persson, B.; Krook, M.; Atrian, S.; Gonzàlez-Duarte, R.; Jeffery, J.; Ghosh, D. Short-chain dehydrogenases/reductases (SDR). Biochemistry 1995, 34, 6003-6013. [CrossRef]

7. Reid, M.F.; Fewson, C.A. Molecular characterization of microbial alcohol dehydrogenases. Crit. Rev. Microbiol. 1994, $20,13-56$. [CrossRef]

8. Elleuche, S.; Antranikian, G. Bacterial group III alcohol dehydrogenases-Function, evolution and biotechnological applications. OA Alcohol 2013, 1, 3. [CrossRef]

9. Radianingtyas, H.; Wright, P.C. Alcohol dehydrogenases from thermophilic and hyperthermophilic archaea and bacteria. FEMS Microbiol. Rev. 2003, 27, 593-616. [CrossRef]

10. Vidal, R.; López-Maury, L.; Guerrero, M.G.; Florencio, F.J. Characterization of an Alcohol Dehydrogenase from the Cyanobacterium Synechocystis sp. Strain PCC 6803 That Responds to Environmental Stress Conditions via the Hik34-Rre1 Two-Component System. J. Bacteriol. 2009, 191, 4383-4391. [CrossRef]

11. Zhang, K.; Yang, X.; Yang, J.; Qiao, X.; Li, F.; Liu, X.; Wei, J.; Wang, L. Alcohol dehydrogenase modulates quorum sensing in biofilm formations of Acinetobacter baumannii. Microb. Pathog. 2020, 148, 104451. [CrossRef]

12. Luong, T.T.; Kim, E.-H.; Bak, J.P.; Nguyen, C.T.; Choi, S.; Briles, D.E.; Pyo, S.; Rhee, D.-K. Ethanol-induced alcohol dehydrogenase $\mathrm{E}$ (AdhE) potentiates pneumolysin in Streptococcus pneumoniae. Infect. Immun. 2015, 83, 108-119. [CrossRef]

13. Bermudez, L.E.; Young, L.S.; Martinelli, J.; Petrofsky, M. Exposure to ethanol up-regulates the expression of Mycobacterium avium complex proteins associated with bacterial virulence. J. Infect. Dis. 1993, 168, 961-968. [CrossRef]

14. Camarena, L.; Bruno, V.; Euskirchen, G.; Poggio, S.; Snyder, M. Molecular mechanisms of ethanol-induced pathogenesis revealed by RNA-sequencing. PLoS Pathog. 2010, 6, e1000834. [CrossRef] [PubMed]

15. Nwugo, C.C.; Arivett, B.A.; Zimbler, D.L.; Gaddy, J.A.; Richards, A.M.; Actis, L.A. Effect of ethanol on differential protein production and expression of potential virulence functions in the opportunistic pathogen Acinetobacter baumannii. PLoS ONE 2012, 7, e51936. [CrossRef] [PubMed]

16. Vidal, R. Alcohol dehydrogenase AdhA plays a role in ethanol tolerance in model cyanobacterium Synechocystis sp. PCC 6803. Appl. Microbiol. Biotechnol. 2017, 101, 3473-3482. [CrossRef]

17. McConnell, M.J.; Actis, L.; Pachón, J. Acinetobacter baumannii: Human infections, factors contributing to pathogenesis and animal models. FEMS Microbiol. Rev. 2013, 37, 130-155. [CrossRef] [PubMed]

18. Wand, M.E.; Bock, L.J.; Turton, J.F.; Nugent, P.G.; Sutton, J.M. Acinetobacter baumannii virulence is enhanced in Galleria mellonella following biofilm adaptation. J. Med. Microbiol. 2012, 61, 470-477. [CrossRef] [PubMed]

19. Insua, J.L.; Llobet, E.; Moranta, D.; Pérez-Gutiérrez, C.; Tomás, A.; Garmendia, J.; Bengoechea, J.A. Modeling Klebsiella pneumoniae pathogenesis by infection of the wax moth Galleria mellonella. Infect. Immun. 2013, 81, 3552-3565. [CrossRef]

20. Conway, T.; Sewell, G.W.; Osman, Y.A.; Ingram, L.O. Cloning and sequencing of the alcohol dehydrogenase II gene from Zymomonas mobilis. J. Bacteriol. 1987, 169, 2591-2597. [CrossRef]

21. Goodlove, P.E.; Cunningham, P.R.; Parker, J.; Clark, D.P. Cloning and sequence analysis of the fermentative alcoholdehydrogenase-encoding gene of Escherichia coli. Gene 1989, 85, 209-214. [CrossRef]

22. Li, D.; Stevenson, K.J. Purification and sequence analysis of a novel NADP(H)-dependent type III alcohol dehydrogenase from Thermococcus strain AN1. J. Bacteriol. 1997, 179, 4433-4437. [CrossRef]

23. Sulzenbacher, G.; Alvarez, K.; Van Den Heuvel, R.H.; Versluis, C.; Spinelli, S.; Campanacci, V.; Valencia, C.; Cambillau, C.; Eklund, H.; Tegoni, M. Crystal structure of E. coli alcohol dehydrogenase YqhD: Evidence of a covalently modified NADP coenzyme. J. Mol. Biol. 2004, 342, 489-502. [CrossRef]

24. González-Segura, L.; Riveros-Rosas, H.; Julián-Sánchez, A.; Muñoz-Clares, R.A. Residues that influence coenzyme preference in the aldehyde dehydrogenases. Chem. Biol. Interact. 2015, 234, 59-74. [CrossRef] [PubMed]

25. Williamson, V.M.; Paquin, C.E. Homology of Saccharomyces cerevisiae ADH4 to an iron-activated alcohol dehydrogenase from Zymomonas mobilis. Mol. Gen. Genet. 1987, 209, 374-381. [CrossRef] [PubMed] 
26. Wills, C.; Kratofil, P.; Londo, D.; Martin, T. Characterization of the two alcohol dehydrogenases of Zymomonas mobilis. Arch. Biochem. Biophys. 1981, 210, 775-785. [CrossRef]

27. Ying, X.; Wang, Y.; Badiei, H.R.; Karanassios, V.; Ma, K. Purification and characterization of an iron-containing alcohol dehydrogenase in extremely thermophilic bacterium Thermotoga hypogea. Arch. Microbiol. 2007, 187, 499-510. [CrossRef] [PubMed]

28. Tasaki, Y.; Yoshikawa, H.; Tamura, H. Isolation and characterization of an alcohol dehydrogenase gene from the octylphenol polyethoxylate degrader Pseudomonas putida S-5. Biosci. Biotechnol. Biochem. 2006, 70, 1855-1863. [CrossRef]

29. An, H.; Scopes, R.K.; Rodriguez, M.; Keshav, K.F.; Ingram, L.O. Gel electrophoretic analysis of Zymomonas mobilis glycolytic and fermentative enzymes: Identification of alcohol dehydrogenase II as a stress protein. J. Bacteriol. 1991, 173, 5975-5982. [CrossRef]

30. Beckham, K.S.H.; Connolly, J.P.R.; Ritchie, J.M.; Wang, D.; Gawthorne, J.A.; Tahoun, A.; Gally, D.L.; Burgess, K.; Burchmore, R.J.; Smith, B.O; ; et al. The metabolic enzyme AdhE controls the virulence of Escherichia coli O157:H7. Mol. Microbiol. 2014, 93, 199-211. [CrossRef]

31. Chen, S.J.; Shu, H.Y.; Lin, G.H. Regulation of tert-Butyl Hydroperoxide Resistance by Chromosomal OhrR in A. baumannii ATCC 19606. Microorganisms 2021, 9, 629. [CrossRef] [PubMed]

32. Aranda, J.; Poza, M.; Pardo, B.G.; Rumbo, S.; Rumbo, C.; Parreira, J.R.; Rodríguez-Velo, P.; Bou, G. A rapid and simple method for constructing stable mutants of Acinetobacter baumannii. BMC Microbiol. 2010, 10, 279. [CrossRef]

33. Hung, Y.P.; Albeck, J.G.; Tantama, M.; Yellen, G. Imaging cytosolic NADH-NAD(+) redox state with a genetically encoded fluorescent biosensor. Cell Metab. 2011, 14, 545-554. [CrossRef]

34. Hung, Y.P.; Yellen, G. Live-cell imaging of cytosolic NADH-NAD+ redox state using a genetically encoded fluorescent biosensor. Methods Mol. Biol. 2014, 1071, 83-95. [CrossRef] [PubMed]

35. Elleuche, S.; Fodor, K.; von der Heyde, A.; Klippel, B.; Wilmanns, M.; Antranikian, G. Group III alcohol dehydrogenase from Pectobacterium atrosepticum: Insights into enzymatic activity and organization of the metal ion-containing region. Appl. Microbiol. Biotechnol. 2014, 98, 4041-4051. [CrossRef]

36. Uthoff, S.; Steinbüchel, A. Purification and characterization of an NAD+-dependent XylB-like aryl alcohol dehydrogenase identified in Acinetobacter baylyi ADP1. Appl. Environ. Microbiol. 2012, 78, 8743-8752. [CrossRef] [PubMed]

37. Herigstad, B.; Hamilton, M.; Heersink, J. How to optimize the drop plate method for enumerating bacteria. J. Microbiol. Methods 2001, 44, 121-129. [CrossRef]

38. Tsai, C.J.; Loh, J.M.; Proft, T. Galleria mellonella infection models for the study of bacterial diseases and for antimicrobial drug testing. Virulence 2016, 7, 214-229. [CrossRef] 